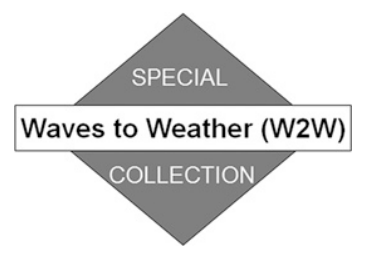

\title{
Evaluation of ECMWF Radiation Scheme Using Aircraft Observations of Spectral Irradiance above Clouds
}

\author{
KeVIN Wolf AND ANDRÉ EHRLICH \\ Leipzig Institute for Meteorology, University of Leipzig, Leipzig, Germany \\ MARIO MECH \\ Institute for Geophysics and Meteorology, University of Cologne, Cologne, Germany \\ ROBIN J. HOGAN \\ European Centre for Medium-Range Weather Forecasts, and Department of Meteorology, University of Reading, \\ Reading, United Kingdom \\ MANFRED WENDISCH \\ Leipzig Institute for Meteorology, University of Leipzig, Leipzig, Germany
}

(Manuscript received 12 December 2019, in final form 28 May 2020)

\begin{abstract}
A novel approach to compare airborne observations of solar spectral irradiances measured above clouds with along-track radiative transfer simulations (RTS) is presented. The irradiance measurements were obtained with the Spectral Modular Airborne Radiation Measurement System (SMART) installed on the High Altitude and Long Range Research Aircraft (HALO). The RTS were conducted using the operational ecRad radiation scheme of the Integrated Forecast System (IFS), operated by the European Centre for MediumRange Weather Forecasts (ECMWF), and a stand-alone radiative transfer solver, the library for Radiative transfer (libRadtran). Profiles of observed and simulated radar reflectivity were provided by the HALO Microwave Package (HAMP) and the Passive and Active Microwave Transfer Model (PAMTRA), respectively. The comparison aims to investigate the capability of the two models to reproduce the observed radiation field. By analyzing spectral irradiances above clouds, different ice cloud optical parameterizations in the models were evaluated. Simulated and observed radar reflectivity fields allowed the vertical representation of the clouds modeled by the IFS to be evaluated, and enabled errors in the IFS analysis data (IFS AD) and the observations to be separated. The investigation of a North Atlantic low pressure system showed that the RTS, in combination with the IFS AD, generally reproduced the observed radiation field. For heterogeneously distributed liquid water clouds, an underestimation of upward irradiance by up to $27 \%$ was found. Simulations of ice-topped clouds, using a specific ice optics parameterization, indicated a systematic underestimation of broadband cloud-top albedo, suggesting major deficiencies in the ice optics parameterization between 1242 and $1941 \mathrm{~nm}$ wavelength.
\end{abstract}

\section{Introduction}

Ice-topped clouds occur in various regions of Earth and cover large areas, e.g., $30 \%$ of the midlatitude troposphere (Wylie and Menzel 1999). Due to their high optical thickness and frequent appearance they play an important role in modulating Earth's radiation budget.

\footnotetext{
Corresponding author: Kevin Wolf, kevin.wolf@uni-leipzig.de
}

They are believed to have a net warming effect on the global average, which is still not fully clear yet (Liou 1986; Zhang et al. 1999). The magnitude of the radiative effects of ice clouds depends mostly on the cloud optical and geometrical thickness, and their total water content. The uncertainty of these factors makes it challenging to quantify their radiative effects. In addition, numerous formation mechanisms lead to complex cloud structures and ice crystal shapes (Wendisch et al. 2007; 
Krämer et al. 2016; Luebke et al. 2016), and the presence of different ice crystal shapes and surface roughness causes further uncertainties in the estimated radiative impact (Wendisch et al. 2005, 2007). Hence, the understanding of these clouds is limited (Voigt et al. 2017).

Despite the effort to improve the knowledge of crucial processes determining the properties and effects of ice clouds by in situ observations, e.g., by Gayet et al. (2002) and Voigt et al. (2017), and remote sensing, e.g., by combined radar-lidar retrievals by Cazenave et al. (2019) as well as the mass-size relations, optical properties, and cloud-radiation interactions of ice clouds are still based on a limited set of measurements and may not represent all possible ice cloud types (Fu 1996; Baum et al. 2005a,b).

In numerical weather prediction (NWP) and global climate models (GCM), ice clouds contribute substantially to model uncertainty and are the components with the lowest confidence (Waliser et al. 2009; Bauer et al. 2015; Stevens and Bony 2013). Therefore, advanced ice cloud parameterizations and model updates are required.

A leading example for continuous model improvement is the Integrated Forecast System (IFS) operated by the European Centre for Medium-Range Weather Forecasts (ECMWF). Evaluations of cloud parameterizations in IFS are commonly performed with ground-based observations at Atmospheric Radiation Measurement (ARM) supersites. These revealed, for example, a systematic underestimation of liquid water content in clouds in the Arctic (Xie et al. 2010; Beesley et al. 2000; Morcrette et al. 2008). However, such ground-based studies are limited to specific locations, being valid for the local area only. In contrast, satellite observations provide a global perspective but at lower spatial and temporal resolution. Comparisons of IFS-simulated solar broadband (0.3-5 $\mu \mathrm{m}$ wavelength) irradiances $F$, in units of watts per square meter, at the top of atmosphere (TOA) against the Clouds and the Earth's Radiant Energy System (CERES) satellite instrument showed systematic underestimation of cloud-top albedo $\alpha$ (defined as the ratio of upward to downward irradiances, $\left.F^{\uparrow} / F^{\downarrow}\right)$ by IFS due to a lack of liquid water content (LWC) at the top of ice clouds in regions affected by cold air outbreaks (Forbes and Ahlgrimm 2014). By adjusting the temperature threshold for ice formation in the IFS microphysics scheme, more LWC is sustained at cloud top (CT), reducing the bias in simulated $\alpha$ (Forbes and Ahlgrimm 2014). The relatively poor temporal, spatial, and spectral resolution of the CERES-derived TOA radiative balance limits the investigation of local radiative effects on subpixel scales. To bridge the gap between satellite and ground-based observations, airborne measurements of spectral irradiance are a useful tool for direct model evaluation. In this regard, some airborne campaigns were conducted, operating instruments to measure the spectral solar radiation reflected by clouds, e.g., Wendisch and Keil (1999), Wendisch et al. (2005, 2007), Jacob et al. (2010), or Smith et al. (2017). In spite of that, the natural variability of clouds might not be covered sufficiently.

However, even when the cloud macrophysical properties are simulated perfectly by an NWP model, e.g., the IFS, the predicted cloud radiative effects might differ from reality due to the radiative transfer scheme. The ice optics parameterization used by the IFS are from $\mathrm{Fu}$ (1996) and Fu et al. (1998), and are known to be prone to errors due to sampling issues, leading to inappropriate mass-size relations (Mitchell et al. 2010; Korolev et al. 2013) and incorrect representation of small ice crystals in the particle size distribution (Korolev et al. 2013). Furthermore, in operational NWP and GCM the surface of ice crystals is commonly assumed to be entirely smooth, which is in contrast to observations performed by Baum et al. (2005a,b). Ice crystals with smooth surfaces have single-scattering phase functions, dominated by forward scattering and an increased asymmetry parameter $g$, while rough ice crystals are characterized by enhanced sideward scattering and reduced $g$. Comparisons of simulations utilizing smooth and rough ice crystals performed by $\mathrm{Fu}$ (2007) indicate differences in simulated upward irradiance $F^{\uparrow}$ by up to $\pm 20 \mathrm{~W} \mathrm{~m}^{-2}$. Wendisch et al. (2007) found that ice crystal shape effects lead to differences in observed upward $F^{\uparrow}$ by \pm 50 to $\pm 60 \mathrm{~W} \mathrm{~m}^{-2}$ in the investigated cases of subtropical ice clouds. Yang et al. (2012) estimated radiative effects in the range of \pm 10 to $15 \mathrm{~W} \mathrm{~m}^{-2}$ due to a reduced $g$.

To advance the continuous development of the IFS radiation scheme (Hogan and Bozzo 2018), a new parameterization called "Yi" is implemented in IFS, which is based on Yang et al. (2013) and Yi et al. (2013), and which considers for ice crystal roughness and different shapes. However, an evaluation against observations is still needed.

Besides ice clouds, the appropriate representation of boundary layer clouds (BLC) is a second challenging aspect for NWP models as they often find it difficult to maintain sufficient LWC in the lowest model grid boxes (Ahlgrimm and Köhler 2010; Ahlgrimm and Forbes 2012). This results in potential underestimation of upward broadband irradiance $F_{\mathrm{BB}}^{\uparrow}$ and broadband cloud-top albedo $\alpha_{\mathrm{BB}}$ by the models (Forbes and Ahlgrimm 2014).

The objective of this paper is to compare spectral upward and downward irradiance $F^{\uparrow}$ and $F^{\downarrow}$, respectively, measured by the Spectral Modular Airborne Radiation Measurement System (SMART) installed on the High Altitude and Long Range Research Aircraft (HALO) during the North Atlantic Waveguide and 
Downstream Impact Experiment (NAWDEX; Schäfler et al. 2018) with along-track simulations of $F^{\uparrow}$ and $F^{\downarrow}$ at flight altitude. The simulations are based on IFS analysis data (IFS AD) and are performed with the radiative transfer solvers ecRad (Hogan and Bozzo 2018) of the IFS and, as a benchmark, the library for Radiative transfer (libRadtran; Emde et al. 2016). The libRadtran simulations apply ice crystal parameterizations by Baum et al. (2005a), based on the same dataset as the IFS "Yi" parameterization but with higher spectral resolution. Therefore, the libRadtran simulations of $F$, based on the Baum parameterization, are regarded as a benchmark for ecRad. The comparison of ecRad and libRadtran simulations, when both are based on the Fu parameterization, are utilized to determine differences in the radiative transfer solvers among ecRad and libRadtran. Both radiative transfer solvers are initialized by the same hourly IFS AD with a spatial grid resolution of $0.1^{\circ}$ $(\approx 9 \mathrm{~km})$. By applying two different models and different cloud ice parameterizations, uncertainties due to the cloud representation in the IFS AD and the radiation schemes themselves are separated.

Furthermore, the vertical cloud structure in the IFS $\mathrm{AD}$ is evaluated by performing forward simulations of radar reflectivity $Z_{\text {sim }}$ with the Passive and Active Microwave Transfer Model (PAMTRA; Mech et al. 2020). These are compared with measured $Z_{\text {obs }}$ from the HALO Microwave Package (HAMP; Mech et al. 2014) instrument. Using the different sensitivities of SMART and HAMP to disparate cloud regions, potential biases in the IFS AD and the ecRad radiation scheme are separated with higher confidence.

The instrumentation of HALO is described in section 2. Section 3 explains the input data used in the simulations and the radiative transfer models ecRad, libRadtran, and PAMTRA as well as their configurations. In section 4, simulated and observed downward irradiance is compared to ensure the appropriate model setup based on cloud-free flight sections. Three cloud cases, observed above a midlatitude cyclone, are analyzed in section 5 with respect to upward $F$ and $\alpha$. The paper is concluded in section 6, followed by a short outlook. Note that Tables 1 and 2 provide lists of symbols and abbreviations used throughout this paper.

\section{Observations}

Observations of spectral upward and downward irradiance were collected with SMART installed on board HALO during NAWDEX (Schäfler et al. 2018), which took place from 19 September to 16 October 2016, and covered the North Atlantic region. For the present study, representative cloud sections observed during research flight 04 (RF04) on 26 September 2016 were selected.
TABLE 1. List of symbols.

\begin{tabular}{|c|c|c|}
\hline Symbol & Long name & Unit \\
\hline$\alpha$ & Spectral cloud-top albedo & $0-1$ \\
\hline$\alpha_{\mathrm{sfc}}$ & Surface albedo & $0-1$ \\
\hline$\chi$ & Radiance ratio $I_{858 \mathrm{~nm}}^{\uparrow} / I_{648 \mathrm{~nm}}^{\uparrow}$ & - \\
\hline$\theta_{0}$ & Solar zenith angle & $\circ$ \\
\hline$\omega_{\lambda}$ & Spectral single-scattering albedo & - \\
\hline$\tau$ & Cloud optical thickness & - \\
\hline$v_{\mathrm{ac}}$ & Aircraft velocity & $\mathrm{m} \mathrm{s}^{-1}$ \\
\hline$f$ & Fractional cloud cover & $0-1$ \\
\hline$f_{\text {tot }, \mathrm{eR}}$ & $\begin{array}{l}\text { Total cloud cover from radiation } \\
\text { scheme }\end{array}$ & $0-1$ \\
\hline$f_{\text {tot,obs }}$ & Total cloud cover from observation & $0-1$ \\
\hline$h_{\mathrm{av}}$ & Aircraft height & $\mathrm{m}$ \\
\hline$p$ & Pressure & $\mathrm{Pa}$ \\
\hline$p_{\text {sfc }}$ & Surface pressure & $\mathrm{Pa}$ \\
\hline$q_{\text {liq }}$ & Liquid water mass-mixing ratio & $\mathrm{kg} \mathrm{kg}^{-1}$ \\
\hline$q_{\text {ice }}$ & Ice water mass-mixing ratio & $\mathrm{kg} \mathrm{kg}^{-1}$ \\
\hline$r_{\text {eff,liq }}$ & Liquid water effective radius & $\mu \mathrm{m}$ \\
\hline$r_{\text {eff,ice }}$ & Ice water effective radius & $\mu \mathrm{m}$ \\
\hline$F$ & Irradiance & $\mathrm{W} \mathrm{m}^{-2}$ \\
\hline$F$ & Spectral irradiance & $\mathrm{W} \mathrm{m}{ }^{-2} \mathrm{~nm}^{-1}$ \\
\hline$I^{\uparrow}$ & Spectral upward radiance & $\mathrm{W} \mathrm{m}{ }^{-2} \mathrm{~nm}^{-1} \mathrm{sr}^{-1}$ \\
\hline IWC & Ice water content & $\mathrm{g} \mathrm{m}^{-3}$ \\
\hline LWC & Liquid water content & $\mathrm{g} \mathrm{m}^{-3}$ \\
\hline$N_{\text {ice }}$ & Ice particle number concentration & $\mathrm{cm}^{-3}$ \\
\hline$T$ & Temperature & $\mathrm{K}$ \\
\hline$T_{\mathrm{sfc}}$ & Surface temperature & $\mathrm{K}$ \\
\hline$U_{10 \mathrm{~m}}$ & $10 \mathrm{~m}$ wind speed in $u$ direction & $\mathrm{m} \mathrm{s}^{-1}$ \\
\hline$V_{10 \mathrm{~m}}$ & $10 \mathrm{~m}$ wind speed in $v$ direction & $\mathrm{m} \mathrm{s}^{-1}$ \\
\hline$Z$ & Radar reflectivity & $\mathrm{dB} Z$ \\
\hline$Z_{\min }$ & $\begin{array}{l}\text { Minimum detectable effective radar } \\
\text { reflectivity }\end{array}$ & $\mathrm{dB} Z$ \\
\hline$Z_{\text {obs }}$ & Measured radar reflectivity & $\mathrm{dB} Z$ \\
\hline$Z_{\text {sim }}$ & Simulated radar reflectivity & $\mathrm{dB} Z$ \\
\hline
\end{tabular}

HALO was equipped with a set of passive and active remote sensing instruments including a spectral radiometer, the spectral imager "spectrometer of the Munich Aerosol Cloud Scanner" (specMACS; Ewald et al. 2016), the HAMP, the Water Vapor Lidar Experiment in Space (WALES; Wirth et al. 2009), and a dropsonde release system (Stevens et al. 2019).

Figure 1 shows the HALO flight track (blue and orange) on a satellite image captured by the Moderate Resolution Imaging Spectroradiometer (MODIS) on the Terra satellite at the time close to the half-way point of RF04 around 1250 UTC. During RF04 the observed low pressure system has been crossed four times to obtain vertical cross sections of the frontal systems and to capture the temporal development of their internal structures (Schäfler et al. 2018).

\section{a. SMART}

SMART measured spectral upward and downward irradiance at flight altitude in the wavelength range between 300 and $2150 \mathrm{~nm}$ (Krisna et al. 2018; Wolf et al. 2017). 
TABLE 2. Abbreviations.

\begin{tabular}{ll}
\hline \hline ARM & Atmospheric Radiation Measurement \\
BLC & Boundary layer cloud \\
CC & Cloud case \\
CCN & Cloud condensation nuclei \\
CFAD & Contour frequency by altitude diagram \\
CERES & Clouds and the Earth's Radiant Energy System \\
CT & Cloud top \\
CTH & Cloud-top height \\
CTP & Cloud-top phase \\
DLR & German Aerospace Center \\
ECMWF & European Centre for Medium-Range Weather \\
& $\quad$ Forecasts \\
ETH & Eidgenösisch Technische Hochschule Zürich \\
GCM & Global climate model \\
GME & Global model \\
HALO & High Altitude and Long Range Research Aircraft \\
HAMP & HALO Microwave Package \\
IFS & Integrated Forecast System \\
IFS AD & IFS analysis data \\
libRadtran & library for Radiative transfer \\
MODIS & Moderate Resolution Imaging Spectroradiometer \\
NAWDEX & North Atlantic Waveguide and Downstream \\
& Impact Experiment \\
NWP & Numerical weather prediction \\
PAMTRA & Passive and Active Microwave Transfer Model \\
RF & Research flight \\
SMART & Spectral Modular Airborne Radiation \\
& Measurement System \\
SOCRATES & Suite of Community Radiative Transfer Codes \\
SPARTACUS & Speedy Algorithm for Radiative Transfer through \\
& Cloud Side \\
TOA & Top of atmosphere \\
\hline &
\end{tabular}

Upward and downward irradiances were collected by optical inlets mounted at the upper and the lower parts of the aircraft fuselage. The upper sensor for $F^{\downarrow}$ (defined for a horizontal plane), was actively stabilized to allow for aircraft movement within $\pm 6^{\circ}$ (Wendisch et al. 2001, 2004). The construction of the two irradiance optical inlets enables to capture the radiation from the upper and lower hemisphere. Additionally, SMART measured spectral upward radiance $I^{\uparrow}$, which was used to derive the cloud-top phase (CTP) following Jäkel et al. (2013). Based on the CTP the observed clouds were classified into liquid water or ice clouds. Measurement uncertainties of irradiances and radiances are composed of errors from absolute calibration and transfer calibration in the field, and are reported to be within $\pm 5 \%$ and $\pm 8 \%$ for the visible and near-infrared wavelength range, respectively (Bierwirth et al. 2013). The measurements were taken with a temporal resolution of $0.5 \mathrm{~s}$. Considering the average aircraft speed of $v_{\mathrm{ac}}=220 \mathrm{~m} \mathrm{~s}^{-1}$ and the field of view of the radiance optical inlet of $2^{\circ}$, the resulting spatial resolution of $I^{\uparrow}$ is $110 \mathrm{~m}$. A cloud mask was derived using the spectral

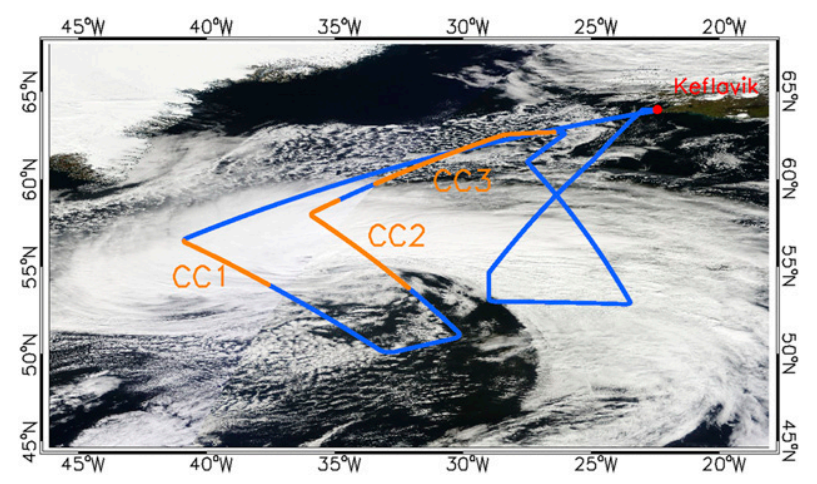

FIG. 1. MODIS Terra satellite image captured at 1250 UTC 26 Sep 2016. HALO flight track of research flight 04 (RF04) is plotted in blue and analyzed flight segments are highlighted in orange.

ratio of $\chi=I_{858 \mathrm{~nm}}^{\uparrow} / I_{648 \mathrm{~nm}}^{\uparrow}$ (Platnick et al. 2013) and utilized to derive a gridbox representative total cloud cover $f_{\text {tot,obs. }}$.

\section{b. HAMP}

HAMP is composed of a suite of passive microwave radiometers and an active cloud radar. The systems are specifically configured for the operation on HALO (Mech et al. 2014). The microwave radiometers include 26 channels between 22.24 and $183.31 \mathrm{GHz} \pm$ $12.5 \mathrm{GHz}$.

The cloud radar MIRA (Ewald et al. 2019; Mech et al. 2020) operates at a frequency of $35 \mathrm{GHz}$ with a horizontal resolution at the ground of about $350 \mathrm{~m}$ in the flight direction and $130 \mathrm{~m}$ across under the assumption of a flight altitude of $12 \mathrm{~km}$, an aircraft speed of $v_{\mathrm{ac}}=$ $220 \mathrm{~m} \mathrm{~s}^{-1}$, and an integration time of $1 \mathrm{~s}$. The vertical range resolution is $30 \mathrm{~m}$. MIRA provides the radar reflectivity $Z_{\mathrm{obs}}$, the linear depolarization ratio, the Doppler velocity, and the spectral width of the particle size distribution. The latter two are strongly affected by aircraft motions, as described in Mech et al. (2014).

\section{Simulations}

Simulated spectral irradiances and $Z_{\text {sim }}$ are based on hourly IFS AD provided on a $0.1^{\circ}$ grid (approximately $9 \mathrm{~km}$ at $40^{\circ} \mathrm{N}$ ). The data assimilation was performed with IFS model cycle 43r1, which was operational between 8 March and 22 November 2016. The IFS AD contains vertical profiles of temperature $T$, pressure $p$, specific humidity $q$, liquid water mass-mixing ratio $q_{\text {liq }}$, rainwater mass-mixing ratio $q_{\mathrm{rw}}$, ice water mass-mixing ratio $q_{\text {ice}}$, snow water mass-mixing ratio $q_{\text {snw }}$, and cloud cover $f$. In this study, only the lowest 99 model levels were fed into the radiative transfer models with the highest level 
at approximately $25 \mathrm{hPa}(28000 \mathrm{~m})$, which is sufficient for precisely simulating the solar irradiance at the flight level. For the surface level, the skin temperature $T_{\mathrm{sfc}}$, skin pressure $p_{\mathrm{sfc}}$, surface albedo $\alpha_{\mathrm{sfc}}$, land-sea mask (LSM), and $10 \mathrm{~m}$ horizontal wind vector were provided.

Aerosol climatologies were not implemented in the IFS radiative transfer simulations (RTS), as RF04 was performed over open ocean and above $11 \mathrm{~km}$ height in unpolluted air masses. Therefore, the impact of aerosol particles on the solar irradiance and the microwave radiation in the observed cases is of minor importance compared to effects by cloud properties and can be neglected. For liquid cloud droplets over open ocean a constant cloud condensation nuclei $(\mathrm{CCN})$ concentration of $50 \mathrm{~cm}^{-3}$ was applied, which was used in IFS until model cycle 32r1. On the basis of the $\mathrm{CCN}$, the cloud liquid effective radius $r_{\text {eff }}$ from the IFS AD was determined, using the parameterizations by Martin et al. (1994) with a correction factor for drizzle (Wood 2000). Ice crystal effective radius was determined from the relations of Sun and Rikus (1999) and Sun (2001).

Vertical profiles of $F$ were simulated with the IFS operational resolution of the 99 lowermost pressure levels. To spatially match the simulations with the actual flight altitude of HALO, the simulated irradiance was linearly interpolated. The simulations of $F$ were conducted with the ECMWF IFS radiation scheme ecRad (Hogan and Bozzo 2018) and the libRadtran (Emde et al. 2016). All simulations were based on the onedimensional (1D) radiative transfer (independent columns), in which lateral photon transport between columns (on grid scale) is not allowed (Cahalan 1994). The approximation is justified for stratiform, homogeneous cloud scenes, e.g., fields of cirrostratus and stratocumulus, where the fraction of photon scattering into neighboring model columns is negligible. Similarly, for clouds with cloud optical thickness $\tau$ above 20, the dominance of absorption reduces photon scattering into nearby model columns (Marshak et al. 1995).

The independent column approximation (ICA) model setup introduces potential deviations between simulated and observed $F^{\uparrow}$, e.g., by neglecting horizontal photon transport. While simulated $F^{\uparrow}$ represents an individual column, the observed upward irradiance is composed of $F^{\uparrow}$ from a larger area. The field of view (FOV) of an instrument is a function of the distance between cloud and aircraft as well as the opening angle of the optical inlet. In extreme cases, with a maximum cloud distance of around $12 \mathrm{~km}$ and a SMART opening angle of $71^{\circ}$ (defined for $90 \%$ of $F^{\uparrow}$ ), the FOV corresponds to an observed area of $70 \mathrm{~km}$ in diameter. This is equal to an area of $9 \times 9$ model columns with an edge length of $0.1^{\circ}$, which is approximately $72 \mathrm{~km} \times 72 \mathrm{~km}$. The effect of the deviating
FOVs was estimated by two representative flight sections. One above high-level stratiform cirrus and another one above a low-level heterogeneous boundary layer cloud field. The two scenes were averaged over the determined area. For the homogeneous cirrus, marginal lower area-averaged irradiances were determined compared to the nadir single-column values. In general, for a cloud fraction above $80 \%$, the relative differences between the single-column and the entire field were below $3 \%$. By contrast, an increased cloud heterogeneity and a maximum distance between aircraft and cloud, led to larger deviations between single-column and fieldaveraged $F^{\uparrow}$ of up to $43 \%$ in extreme cases.

The input data of the radiative transfer simulations were extracted from the gridded three-dimensional (3D), hourly IFS AD by choosing the closest match between aircraft location and model grid point. To account for temporal changes between two IFS time steps, the hourly fields of the IFS AD, were linearly interpolated on the measurement time $t(i)$.

Spectral surface albedo $\alpha_{\text {sfc }}$ was determined for each model column as a function of solar zenith angle $\theta_{0}$ following the parameterization of Taylor et al. (1996). Spectral top of atmosphere irradiance $F_{\text {TOA }}^{\downarrow}$ was provided by Kurucz (1992).

\section{a. ecRad configuration}

The radiative transfer calculations were computed by the Tripleclouds solver (Shonk and Hogan 2008), which is different from the operational IFS solver but produces similar results and allows vertical profiles of $F$ to be calculated for all spectral bands. It treats the scattering phase function of nonspherical particles by the deltaEddington approximation (Joseph et al. 1976).

The ecRad Tripleclouds solver does not support the operational exponential-exponential cloud overlap assumption (COA). Therefore, the exponentialrandom COA was applied here, which is closest to the operational configuration and suitable for the analyzed cloud types.

Gas optical properties were treated on basis of the Rapid Radiative Transfer Model for GCMs (RRTMG; Mlawer et al. 1997), from which the spectral resolution of ecRad is derived.

Cloud optical properties of liquid water droplets are represented by the Suite of Community Radiative Transfer codes based on Edwards and Slingo (1996) scheme. Two different parameterizations of ice crystal optical properties were applied: the operational parameterization by ecRad of $\mathrm{Fu}$ (1996), Fu et al. (1998), and Sun and Fu (2001) and the Yi ice optics after Yi et al. (2013), which is an updated but still experimental scheme. 
To visualize the spectral difference between the $\mathrm{Fu}$, Yi, and Baum ice optics parameterization, Fig. 2 presents the single-scattering albedo $\tilde{\omega}$ for ice crystals with particle sizes $r_{\text {eff }}$ of 20,40, and $60 \mu \mathrm{m}$. Integrating the original $\mathrm{Fu}$ ice scheme of spectral $\tilde{\omega}$ onto the ecRad band resolution leads to potential errors, as only few values (three to four data points) represent the spectral dependence of $\tilde{\omega}$. This becomes obvious for wavelengths larger than $1200 \mathrm{~nm}$, particularly in the absorption wavelengths. For Baum and Yi parameterizations, the optical properties are precalculated on a higher spectral resolution of about $10 \mathrm{~nm}$, with potentially smaller integration errors and taking better account of the water and ice absorption features of $\tilde{\omega}$.

Further description of IFS treatment of the cloud macrophysics and the implementation of the radiation scheme ecRad, are given by Beljaars et al. (2018), and Hogan and Bozzo (2018). The ecRad configuration was chosen according to Table 2 in Hogan and Bozzo (2018).

\section{b. libRadtran configuration}

The libRadtran simulations were configured to comply with the operational IFS model runs. Simulations were based on the IFS AD introduced above, applying the same $r_{\text {eff }}$ for liquid water droplets and ice crystals, and surface albedo $\alpha_{\text {sfc }}$ as ecRad. Irradiance of all libRadtran simulations was calculated with the Discrete Ordinate Radiative Transfer model (DISORT) 2.0 solver (Stamnes et al. 2000) with 16 streams, while ecRad applies the two stream method. To estimate the influence of a different number of streams, libRadtran was additionally operated in two-stream mode for that purpose. No significant differences for $F_{\mathrm{BB}}^{\uparrow}$ were found between the libRadtran 2 stream and 16 stream, as well as the ecRad simulations. The relative differences range below $\pm 2 \%$. Therefore, the libRadtran reference simulations are performed with 16 streams. From the marginal differences in $F$ it is concluded that ecRad provides sufficient accuracy applying two-stream calculations to consider solar zenith angles (SZAs) below $60^{\circ}$ (Joseph et al. 1976). libRadtran simulations cover a wavelength range from 263 to $2150 \mathrm{~nm}$ with a spectral resolution is $1 \mathrm{~nm}$. The spectral simulations of libRadtran were integrated over the spectral bands of ecRad.

A random cloud overlap was assumed, using the "rand" scheme, which is not consistent with the operational IFS configuration but of small influence in case of the observed stratiform cloud fields. Optical properties of liquid water clouds were represented by precalculated Mie tables (Mie 1908). For ice crystals, two ice crystal optical parameterizations were applied. Complementary to IFS, columnar ice crystals were determined on the basis of the generalized effective ice particle size

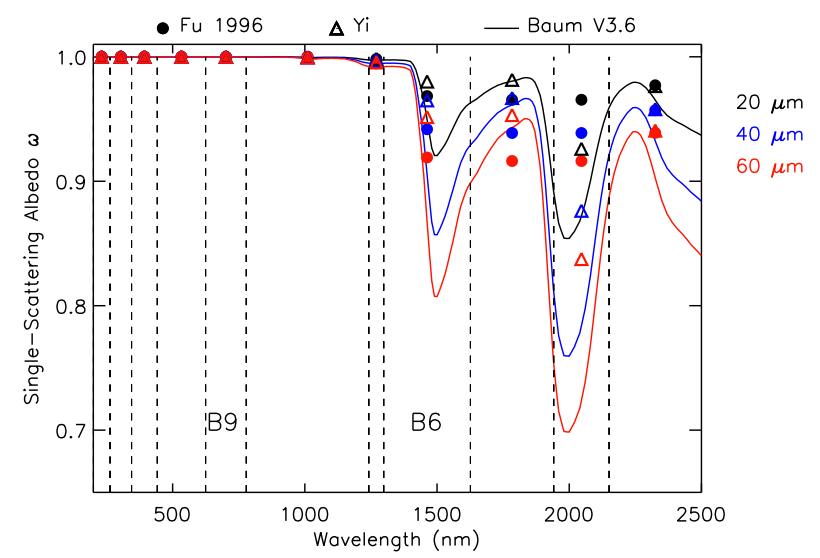

FIG. 2. Simulated spectral single-scattering albedo $\tilde{\omega}$ for ice crystals with sizes of 20,40 , and $60 \mu \mathrm{m}$ between 200 and $2500 \mathrm{~nm}$ by ecRad for Fu (1996) (dots) and Yi et al. (2013) (triangles), and by libRadtran for Baum et al. (2007) (solid). Dashed vertical lines represent the boundaries of the ecRad spectral bands.

definition after $\mathrm{Fu}(1996)$ and $\mathrm{Fu}$ et al. (1998). There, the size of a hexagonal ice particle is given by the length of the maximum dimension. For more realistic benchmark simulations, the "general habit mixture" of Baum et al. (2005a,b) was used, applying full scattering phase functions. Furthermore, the comparison of ecRad Fu and libRadtran Fu simulations of $F^{\uparrow}$ allowed to determine the differences in the simulated irradiance, which arise from the different RTS in the models. Potential discrepancies between simulations of libRadtran and ecRad only arise from differences in the cloud optics parameterization and the RTS itself. In case both models agree, deviations between simulations and observations must arise from the cloud representation in the IFS AD.

\section{c. Simulations of radar reflectivity with the PAMTRA}

The cloud vertical structure from the IFS AD was evaluated by comparing radar reflectivities $Z$ observed by the MIRA radar of HAMP with the PAMTRA (Mech et al. 2020) simulations. PAMTRA is a onedimensional radiative transfer simulator for passive and active applications in cloudy and precipitating atmospheres applying the independent column approximations for upward and downward looking geometries. It simulates, for the whole microwave frequency range, the brightness temperatures or irradiances in passive mode or the radar reflectivity, the full Doppler spectrum, and higher moments of the spectrum in active mode. By default, it uses the model by Rosenkranz (2015) for gaseous absorption with modifications by Turner et al. (2009) and Liljegren et al. (2005). The single-scattering properties of an unlimited number of hydrometeor classes can be calculated for the passive and active simulations 
by various methods such as Mie theory (Mie 1908), the T-matrix method (Mishchenko and Travis 1994), the self-similar Rayleigh-Gans approximation (Hogan et al. 2017), or by using predefined databases. For the surface emissivity, options for land and ocean surfaces are included. To couple to various input sources, a collection of interfaces to atmospheric models or in situ measurements are included.

For the application shown in this manuscript assumptions on hydrometeors follow the ones in the microphysical scheme of the IFS and were adapted according to assumptions made in Di Michele et al. (2012). The particle size distribution of snow is implemented according to Field et al. (2007). The rain droplet size distribution is assumed to be exponentially. The scattering properties of snow and ice crystals are calculated with the self-similar Rayleigh-Gans method.

Simulations of $Z$ were corrected for the rangedependent minimum detectable effective reflectivity $Z_{\text {min }}$, taking the HAMP radar sensitivity into account (Ewald et al. 2019). Radar reflectivity $Z_{\text {sim }}$ was determined by Eq. (26) given in Ewald et al. (2019).

\section{Comparison of downward irradiance and cloud cover}

In the subsequent sections simulated irradiances are indexed in the following way:

Upward and downward irradiance are indicated by $F^{\uparrow}$ and $F^{\downarrow}$, respectively. Broadband $(300-2150 \mathrm{~nm}) F$ are labeled with subscript $\mathrm{BB}$, while $F$ for spectral bands of RRTMG are labeled with "B6" and "B9" for wavelength ranges of 1298-1626 and 625-777 nm, respectively. The simulations of ecRad and libRadtran are identified by "eR" and "lib." The ice optics parameterizations by Fu et al. (1998), Baum et al. (2005a), and Yi et al. (2013) are labeled with "Fu," "Ba," and "Yi," respectively. Measured $F$ use the index "obs."

\section{a. Downward irradiance}

To test the setup and general performance of the radiative transfer models without impact of clouds, the spectral downward irradiance $F^{\downarrow}$ at flight level was simulated and compared to the observation. Above HALO, cloud-free conditions prevailed during RF04. Figure 3 shows the normalized probability density function (PDF) of broadband solar irradiance (downward) simulated by ecRad $F_{\mathrm{BB}, \mathrm{eR}}^{\downarrow}$ (blue), libRadtran $F_{\mathrm{BB}, \mathrm{lib}}^{\downarrow}$ (green), and measured by SMART $F_{\mathrm{BB}, \text { obs }}^{\downarrow}$ (black). The width of the distributions is determined by changes of the solar zenith angle along the flight track. The PDFs of $F_{\mathrm{BB}}^{\downarrow}$ agree with respect to the features of the distribution, indicating that the simulations and measurements of $F_{\mathrm{BB}}^{\downarrow}$

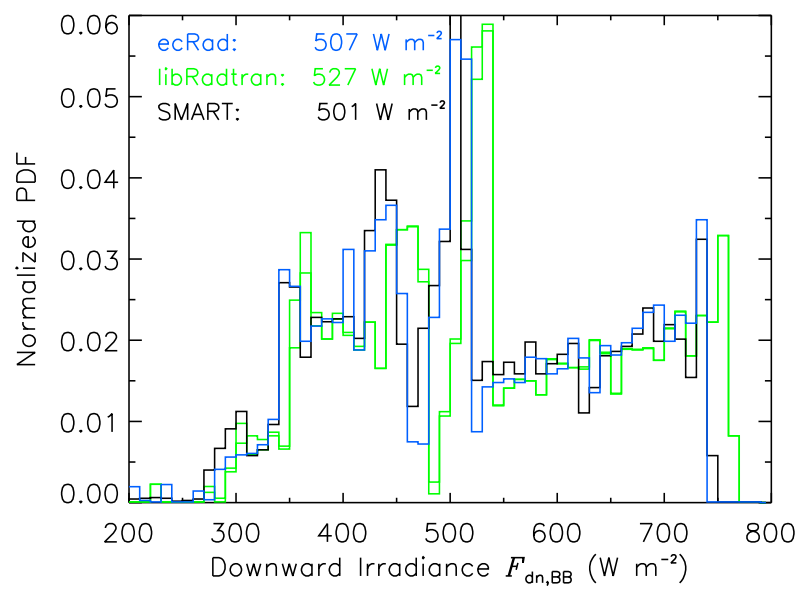

FIG. 3. Normalized probability density function (PDF) of broadband downward solar irradiance derived from SMART (black), ecRad (blue), and libRadtran (green) of research flight 26 Sep 2016.

are consistent. However, mean values of the models differ slightly, with the libRadtran simulations being shifted to higher values by $20 \mathrm{~W} \mathrm{~m}^{-2}$ with respect to ecRad, exhibiting a systematic offset.

PDFs of irradiances from ecRad and SMART almost match each other. The systematic bias of $F_{\mathrm{BB}, \mathrm{lib}}^{\downarrow}$ results from different atmospheric profiles of temperature $T$, pressure $p$, and humidity $q$ above $28 \mathrm{~km}$ height. Further deviations are related to a diverging representation of Rayleigh scattering and molecular absorption within libRadtran and ecRad, whereby libRadtran performs these calculations with high internal spectral resolution and on basis of Bodhaine et al. (1999). The offset of $20 \mathrm{~W} \mathrm{~m}^{-2}$ is within the model and measurement uncertainty of SMART $( \pm 5 \%)$ and regarded to be negligible with respect to the dominating radiative effects of clouds.

\section{b. Cloud cover}

Upward irradiance $F^{\uparrow}$ is predominantly determined by the reflection due to clouds, which is a function of the (total) cloud cover $f_{\text {tot }}$. In the simulations, the horizontal distribution of clouds in partly cloud-covered grid boxes is specified by the COA. To evaluate the applied exponential-random (EXP-RAN) COA in the ecRad simulations, $f_{\text {toter }}$ of the atmospheric column was compared to observations by SMART, which base on individual measurements, flagged as cloudy or cloud free. Total cloud cover from SMART and resulting PDFs are determined by calculating a running mean over 50 consecutive measurements.

Figure 4 presents normalized PDFs of $f_{\text {tot,eR }}$ diagnosed from the ecRad solver (blue), applying the "EXPRAN" COA, and SMART derived $f_{\text {tot,obs }}$ (black) for the entire RF04. The normalized PDF of $f_{\text {tot,obs }}$ is almost 


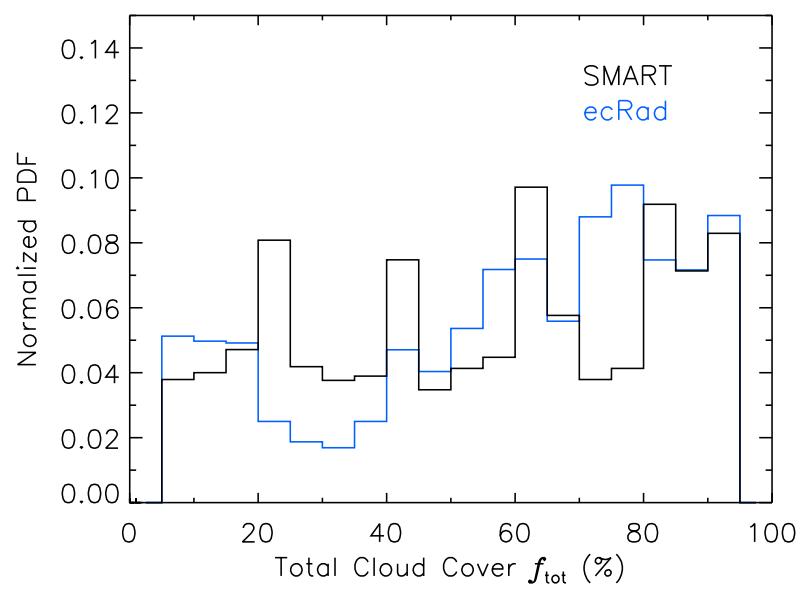

FIG. 4. Normalized PDF of total cloud cover diagnosed from the ecRad solver $f_{\text {tot,eR }}$ (blue) and the SMART cloud mask $f_{\text {tot,obs }}$ (black) for RF04.

equally distributed for all values of $f_{\text {tot }}$, while the distribution of $f_{\text {tot,eR }}$ is skewed to large values of $f_{\text {tot }}$. The median cloud fractions of the simulations and observations amount to $f_{\text {tot, } \mathrm{eR}}=79.7 \%$ and $f_{\text {tot,obs }}=76.6 \%$, indicating that the location and distribution of the modeled cloud field was very close to the observations. From the remaining difference of $4 \%$ it is concluded that the applied COA EXP-RAN in ecRad causes only a slight overestimation for the stratiform cloud conditions during RF04. To minimize a potential impact of cloud fraction on the comparison later in this paper, only ice cloud sections were selected, where $f_{\text {tot }}$ was above $80 \%$.

\section{Comparison of upward irradiance and cloud-top albedo}

Figure 5 shows the time series of measurements and simulations collected during RF04 between 1045 and 1445 UTC, where individual sections with liquid water and ice clouds were observed. During this time HALO crossed the warm conveyor belt (WCB) of a low pressure system from southeast to northwest, flew over an area with heterogeneous stratus patches located within a cold air outbreak, and then crossed the WCB farther north in the opposite flight direction. The second WCB passage was followed by another section of boundary layer stratocumulus. Two sections of RF04, labeled cloud case 1 (CC1) and cloud case 2 (CC2) (marked by the gray boxes), were selected to analyze the spectral representation of ice-topped clouds in more detail. The representation of boundary layer clouds (BLC) is investigated for cloud case 3 (CC3).

At the top horizontal axis of Fig. 5a the traveled along-track distance is provided in kilometers. In Fig. 5a the upward broadband irradiance from SMART $F_{\mathrm{BB} \text {,obs }}^{\uparrow}$ (black), ecRad Fu $F_{\mathrm{BB}, \mathrm{eR}, \mathrm{Fu}}^{\uparrow}$ (dark blue), ecRad Yi $F_{\mathrm{BB}, \mathrm{eR}, \mathrm{Yi}}^{\uparrow}$ (light blue), libRadtran $\mathrm{Fu} F_{\mathrm{BB}, \mathrm{lib}, \mathrm{Fu}}^{\uparrow}$ (orange), and libRadtran Baum $F_{\mathrm{BB}, \mathrm{lib}, \mathrm{Ba}}^{\uparrow}$ (green) are given. Figure $5 \mathrm{~b}$ shows spectral $F_{\mathrm{B} 6}^{\uparrow}(1298-1626 \mathrm{~nm})$. Vertical profiles of LWC and ice water content (IWC) from the IFS AD are displayed in Figs. 5c and 5d. Radar reflectivity $Z_{\text {obs }}$ measured by HAMP is plotted in Fig. 5e, with the cloud-top height (CTH) from the RTS indicated by the red line. In Fig. $5 \mathrm{f}$ simulated $Z_{\text {sim }}$ from PAMTRA is given.

SMART measured higher broadband and spectral values of upward irradiance compared to all simulations. For the first crossing of the WCB (1045-1215 UTC, $\mathrm{CC} 1$ ), simulated and observed $F_{\mathrm{BB}}^{\uparrow}$ and $F_{\mathrm{B} 9}^{\uparrow}$ agree within the SMART measurement uncertainty of $\pm 5 \%$. For $F_{\mathrm{B} 6}^{\uparrow}$ a significant underestimation by $F_{\mathrm{BB}, \mathrm{eR}, \mathrm{Fu}}^{\uparrow}$ appears, followed by $F_{\mathrm{BB}, \mathrm{eR}, \mathrm{Yi}}^{\uparrow}$ and $F_{\mathrm{BB}, \mathrm{lib}, \mathrm{Fu}}^{\uparrow}$. Good agreement is apparent for $F_{\mathrm{BB}, \mathrm{lib}, \mathrm{Ba}}$, which is within the SMART uncertainty range. The same spectral features were observed for the second crossing of the WCB (1340-1425 UTC, $\mathrm{CC} 2$ ). Both sections were characterized by clouds dominated by ice at cloud top. The appearance of the deviation in both ice sections ( $\mathrm{CC} 1$ and $\mathrm{CC} 2)$ is an indicator of deficiencies in the ecRad and libRadtran Fu ice optics parameterization, which requires a more detailed investigation. The discrepancy in the liquid water case (CC3), between simulated and observed upward irradiance, points toward an required improvement of boundary layer clouds in the IFS cloud module, to better represent the local radiative effects of these clouds.

Time series of vertical profiles of LWC and IWC from the IFS AD are shown in Figs. 5c and 5d, respectively, revealing a much lower fraction of liquid than ice clouds. For the WCB two local maxima around 1200 and 1340 UTC between 1000 and $5000 \mathrm{~m}$ altitude appear. Accordingly, cloud layers with larger values of $Z_{\text {obs }}$ were detected in the same locations (see Fig. 5e). In general, the observed and simulated cloud structures represented by $Z$ match, although low-level clouds with low LWC are missing in $Z_{\mathrm{obs}}$ compared to the simulations due to the minimum radar detection threshold.

Figure 6 shows PDFs of simulated and measured solar upward irradiance from ecRad $\mathrm{Fu} F_{\mathrm{BB}, \mathrm{eR}, \mathrm{Fu}}^{\uparrow}$ (blue), ecRad Yi $F_{\mathrm{BB}, \mathrm{e}, \mathrm{Yi}}^{\uparrow}(\mathrm{red})$, libRadtran Fu $F_{\mathrm{BB}, \mathrm{lib}, \mathrm{Fu}}^{\uparrow}$ (orange), libRadtran Baum $F_{\mathrm{BB}, \text { lib,Ba }}^{\uparrow}$ (green), and SMART $F_{\mathrm{BB}, \mathrm{obs}}^{\uparrow}$ (black) of the entire flight.

The median of the observed $F_{\mathrm{BB}, \mathrm{obs}}^{\uparrow}$ from entire flight, with $245 \mathrm{~W} \mathrm{~m}^{-2}$, is generally higher compared to all simulations. The smallest deviations between simulations and observations appear for $F_{\mathrm{BB}, \mathrm{lib}, \mathrm{Ba}}^{\uparrow}$, which is lower by $4.5 \%$, and followed by $F_{\mathrm{BB}, \mathrm{lib}, \mathrm{Fu}}^{\uparrow}$, which is lower by $6.9 \%$, with respect to the measurements. A larger bias appears for the ecRad simulations utilizing the $\mathrm{Yi}$ 

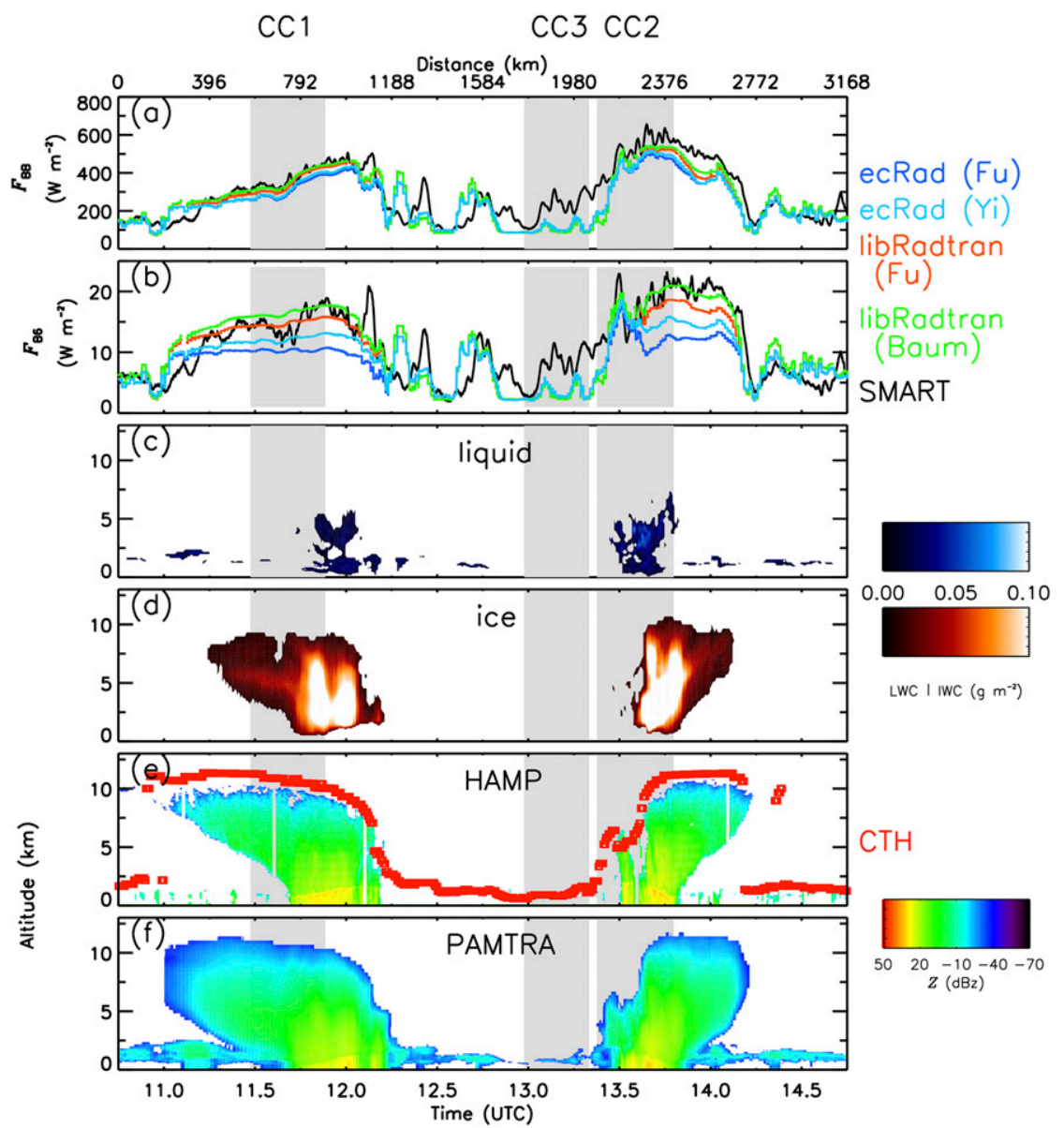

FIG. 5. Time series of research flight 04 between 1045 and 1445 UTC. The covered flight distance $(\mathrm{km})$ is given at the top. (a),(b) The measured and simulated spectral irradiance $F^{\uparrow}$. The ecRad Fu simulations are represented by the dark blue line and the ecRad Yi simulations are indicated by the light blue line, while the libRadtran simulations with $\mathrm{Fu}$ and Baum are given in red and green, respectively. (c),(d) The IFS-based liquid water content (LWC) and ice water content (IWC), respectively. (e),(f) The measured and simulated radar reflectivity $Z$, respectively. In (e) the IFS-derived cloud-top height is indicated by the red line. Analyzed flight sections are highlighted in gray.

and $\mathrm{Fu}$ ice optics parameterizations with relative differences of $-11.8 \%$ and $-12.2 \%$, respectively.

The comparison among the models shows that the distributions of $F_{\mathrm{BB}, \mathrm{eR}, \mathrm{Fu}}^{\uparrow}$ and $F_{\mathrm{BB}, \mathrm{eR}, \mathrm{Yi}}^{\uparrow}$ (Fig. 6a) are slightly shifted to lower irradiance values with a median of 215 and $216 \mathrm{~W} \mathrm{~m}^{-2}$ compared to the observations by SMART, respectively. For the entire flight, the median of $F_{\mathrm{BB}, \mathrm{eR}, \mathrm{Fu}}^{\uparrow}$ is lower by $8.1 \%$ and for $F_{\mathrm{BB}, \mathrm{eR}, \mathrm{Yi}}^{\uparrow}$ the median is lower by $7.7 \%$ compared to $F_{\mathrm{BB}, \mathrm{lib}, \mathrm{Ba}}^{\uparrow}$. Higher values of $F_{\mathrm{BB}}^{\uparrow}$ are simulated by libRadtran using the Fu and Baum parameterization (Fig. 6b), leading to medians of similar value of 228 and $234 \mathrm{Wm}^{-2}$ (Fig. 6b), respectively. Among both libRadtran simulations, only minor relative differences of up to $-3.8 \%$ are detected, which are solely caused by the difference in the ice optics parameterizations of $\mathrm{Fu}$ and Baum. As both libRadtran simulations are based on the same IFS AD and Mie optics, no difference in upward irradiance appears for the liquid water clouds.

Furthermore, higher median values of $f_{\text {tot,eR }}$ compared to $f_{\text {tot,obs }}$ indicate more clouds in the IFS AD (Fig. 4), while the median of irradiance simulated by ecRad is reduced with respect with the observations. This indicates, that either cloud properties such as total water path (TWP) and phase differ from the observations, or the radiative transfer models. The higher values of upward irradiance by both libRadtran parameterizations compared to the results from the ecRad simulations are in accordance with the bias in downward irradiance, where $F_{\mathrm{BB}, \text { lib }}^{\downarrow}$ is larger than $F_{\mathrm{BB}, \mathrm{e} R}^{\downarrow}$, which is biasing the resulting $F^{\uparrow}$. To avoid this, $F^{\uparrow}$ can be normalized by $F^{\downarrow}$, defined as the albedo, which is additionally applied in the comparison. 


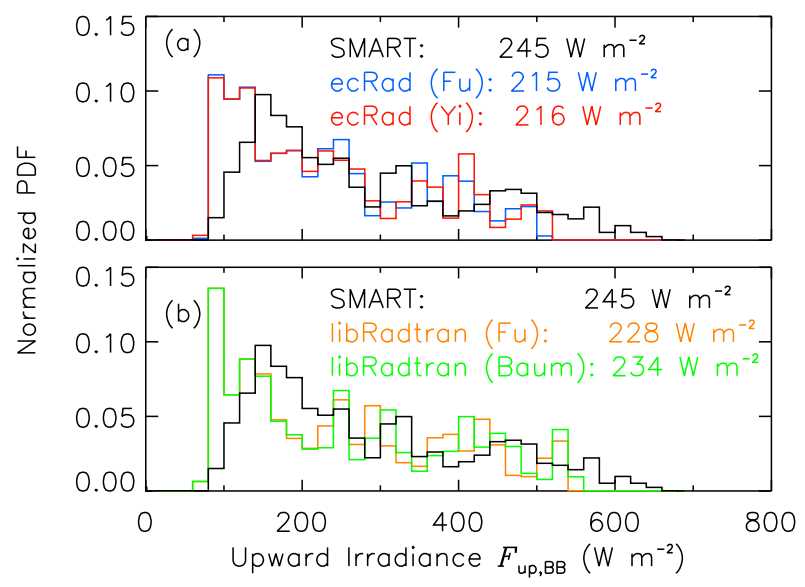

FIG. 6. Normalized PDF of broadband upward solar irradiance derived from (a) SMART, ecRad Fu, and ecRad Yi, and (b) SMART, libRadtran Fu, and libRadtran Baum of the entire RF04.

The relative difference between both $F_{\mathrm{BB}, \mathrm{eR}, \mathrm{Fu}}^{\uparrow}$ and $F_{\mathrm{BB}, \mathrm{eR}, \mathrm{Yi}}^{\uparrow}$, and $F_{\mathrm{BB}, \mathrm{obs}}^{\uparrow}$ exceed the SMART uncertainty range (lower values of $F^{\uparrow}$ are overestimated, high values of $F^{\uparrow}$ are underestimated), indicating that ecRad is not able to reproduce the sensitivity of $F^{\uparrow}$ to variations in LWC and IWC. The overestimation of lower values of $F_{\mathrm{BB}, \mathrm{eR}}^{\uparrow}$ is partly related to the overestimation of model columns with $f_{\text {tot }}$ below $20 \%$ (Fig. 4).

A more striking feature in the time series of upward irradiance (Figs. 5a,b) is the systematically lower simulated $F^{\uparrow}$ by ecRad of ice-topped clouds compared to the simulations by libRadtran and the SMART observations, in particular for spectral band 6. This implies ecRad has difficulties in simulating the radiative properties of clouds with ice in the upper most cloud layer. Therefore, $F_{\mathrm{BB}}^{\uparrow}$ is separated for ice and liquid water topped clouds. The median values of $F^{\uparrow}$ for the individual ice optics parameterizations are given in Table 3. Relative differences are calculated with respect to the SMART measurements.

For the liquid water cloud section (CC3 in Fig. 5) a significantly higher median observed $F_{\text {obs }}^{\uparrow}$ with a relative difference of $+33 \%$ is recorded, which requires a more detailed analysis. This cloud section was dominated by optically thin and heterogeneously distributed patches of low-level BLC. Appropriate representation of BLC is challenging as the IFS cloud module is known for its deficiency in maintaining sufficient LWC in the lower model grid boxes (Forbes and Ahlgrimm 2014), which is seen as the main reason for the systematic underestimation of $F^{\uparrow}$ compared to the observations.

The separation of $F_{\mathrm{BB}, \mathrm{eR}, \mathrm{Fu}}^{\uparrow}$ for liquid water and ice at CT reveals relative differences of $-1.6 \%$ and $-13.1 \%$ in relation to the respective libRadtran Baum simulations. This shows that the underestimation in $F_{\mathrm{BB}, \mathrm{eR}}^{\uparrow}$ is mostly detected in regions with ice-topped clouds, indicating potential discrepancies in the ice optics parameterizations in ecRad. The same feature is present for the ecRad Yi ice parameterization with larger relative differences mostly caused by the ice-topped clouds.

To investigate the spectral representation of icetopped clouds in more detail, two representative flight sections $\mathrm{CC} 1$ and $\mathrm{CC} 2$ (Fig. 5, gray) are discussed in more detail. For $\mathrm{CC} 1$ and $\mathrm{CC} 2$ the microphysical and macrophysical properties, SZA, and flight parameters are listed in Table 4.

\section{a. Ice cloud case 1}

Cloud case 1 (CC1), indicated by the first gray box in Fig. 5, contains 750 simulated time steps and 3000 individual SMART measurements. For $\mathrm{CC} 1$ the mean solar zenith angle $\overline{\theta_{0}}$ was determined to be $65.2^{\circ}$ and varied by $\Delta \theta_{0}=2.9^{\circ}$ only, and therefore the solar zenith angle was assumed to be constant.

Time series of $F_{\mathrm{BB}}^{\uparrow}$ in Fig. 5a and the radar image in Fig. 5e reveal a quite homogeneous cloud structure with increasing geometric thickness along the flight track. CTP from SMART, MODIS, and the IFS AD indicate the presence of ice for the entire period, supported by the absence of LWC at higher altitudes (Fig. 5c). Measured $F_{\mathrm{BB}, \mathrm{obs}}^{\uparrow}$ increases with time from 350 to a maximum of $500 \mathrm{~W} \mathrm{~m}^{-2}$ around $1201 \mathrm{UTC}$, decreasing afterward due to a weakening cloud structure. Only slight fluctuations in $F_{\mathrm{BB}, \mathrm{obs}}^{\uparrow}$ are present. All simulated $F_{\mathrm{BB}}^{\uparrow}$ follow the observations, with $F_{\mathrm{BB}, \mathrm{lib}, \mathrm{Fu}}^{\uparrow}$ and $F_{\mathrm{BB}, \mathrm{lib}, \mathrm{Ba}}^{\uparrow}$ being nearly identical to $F_{\mathrm{BB}, \mathrm{obs}}^{\uparrow}$.

The spectral cloud-top albedo $\alpha$ is a measure for the radiative impact of a cloud. Figures $7 \mathrm{a}-\mathrm{i}$ depict PDFs of

TABLE 3. Median values of broadband upward irradiances $F^{\uparrow}$ of the entire research flight on 26 Sep 2016 separated for ice and liquid water sections. Relative deviations refer to the SMART measurements.

\begin{tabular}{lllccc}
\hline \hline & & & All & Ice & Liquid \\
\hline ecRad & $\mathrm{Fu}$ & $F_{\mathrm{BB}, \mathrm{eR}, \mathrm{Fu}}^{\uparrow}\left(\mathrm{W} \mathrm{m}^{-2}\right)$ & $214.6(-12.4 \%)$ & $317.3(-15.5 \%)$ & $135.5(-27.2 \%)$ \\
& $\mathrm{Yi}$ & $F_{\mathrm{BB}, \mathrm{R}, \mathrm{Yi}}\left(\mathrm{W} \mathrm{m}^{-2}\right)$ & $215.7(-11.9 \%)$ & $325.5(-13.3 \%)$ & $135.5(-27.2 \%)$ \\
libRadtran & $\mathrm{Fu}$ & $F_{\mathrm{BB}, \mathrm{lib}, \mathrm{Fu}}\left(\mathrm{W} \mathrm{m}^{-2}\right)$ & $227.7(-7.0 \%)$ & $351.3(-6.4 \%)$ & $137.7(-26.0 \%)$ \\
& $\mathrm{Baum}$ & $F_{\mathrm{BB}, \mathrm{lib}, \mathrm{Ba}}\left(\mathrm{W} \mathrm{m}^{-2}\right)$ & $233.8(-4.5 \%)$ & $365.2(-2.69 \%)$ & $137.7(-26.0 \%)$ \\
SMART & & $F_{\mathrm{BB}, \mathrm{obs}}\left(\mathrm{W} \mathrm{m}^{-2}\right)$ & 244.9 & 375.3 & 186.2 \\
\hline
\end{tabular}


TABLE 4. Mean and median liquid water path (LWP), ice water path (IWP), cloud-top height (CTH), solar zenith angle (SZA), and flight parameters for the selected ice cloud cases.

\begin{tabular}{lcc}
\hline \hline & Cloud case 1 & Cloud case 2 \\
\hline Samples (simulation) & 750 & 660 \\
Samples (observation) & 3000 & 2640 \\
LWP mean $\left(\mathrm{kg} \mathrm{m}^{-2}\right)$ & 0.422 & 0.341 \\
LWP median $\left(\mathrm{kg} \mathrm{m}^{-2}\right)$ & 0.500 & 0.133 \\
IWP mean $\left(\mathrm{kg} \mathrm{m}^{-2}\right)$ & 2.412 & 2.408 \\
IWP median $\left(\mathrm{kg} \mathrm{m}^{-2}\right)$ & 2.534 & 2.021 \\
$r_{\text {eff }}(\mu \mathrm{m})$ & 29.3 & 32.1 \\
CTH $(\mathrm{km})$ & 9.9 & 10.9 \\
SZA $\left({ }^{\circ}\right)$ & 65.2 & 59.3 \\
Flight altitude $(\mathrm{km})$ & 12.4 & 12.5 \\
\hline
\end{tabular}

$\alpha$ calculated from SMART measurements (black), ecRad Fu simulations (solid blue), ecRad Yi simulations (dotted blue), and libRadtran simulations using the $\mathrm{Fu}$ (orange) and Baum (green) parameterization. The first column shows broadband $\alpha_{\mathrm{BB}}$ and subsequent columns present $\alpha$ for spectral band B9 (dominated by scattering) and band B6 (dominated by absorption).

Table 5 summarizes the statistical parameters of the upward irradiance and cloud albedo results observed and simulated during $\mathrm{CC}$.

Broadband $\alpha_{\mathrm{BB}, \mathrm{obs}}$ from SMART is generally higher compared to all simulations, indicated by the peak of the PDF being around 0.84 (Fig. 7). Simulated $\alpha_{\mathrm{BB}, \mathrm{eR}, \mathrm{Fu}}$ and $\alpha_{\mathrm{BB}, \mathrm{eR}, \mathrm{Yi}}$ agree among each other but are shifted to lower values by 0.09 with respect to $\alpha_{\mathrm{BB}, o b s}$ and a peak of around 0.72. PDFs of libRadtran Fu $\alpha_{\mathrm{BB}, \mathrm{lib}, \mathrm{Fu}}$ and Baum $\alpha_{\mathrm{BB}, \mathrm{lib}, \mathrm{Ba}}$ show a similar shape as $\alpha_{\mathrm{BB}, \mathrm{eR}, \mathrm{Fu}}$, being shifted to lower values by 0.1 and 0.06 compared to $\alpha_{\mathrm{BB}, \mathrm{obs}}$, respectively.

In the second column, $\alpha_{\mathrm{B} 9}$ of spectral band $\mathrm{B} 9$ is shown. Cloud-top albedo $\alpha_{\mathrm{B} 9 \text {,obs }}$ shows highest values with a peak at 0.91 , while all models have lower median values with $\alpha_{\mathrm{B} 9, \mathrm{eR}, \mathrm{Fu}}=0.83, \alpha_{\mathrm{B} 9, \mathrm{lib}, \mathrm{Fu}}=0.87$, and $\alpha_{\mathrm{B} 9 \text {,lib,Ba }}=0.89$. The shapes of $\alpha_{\mathrm{B} 9}$ from both models and ice optics parameterizations appear to be nearly identical, similar to $\alpha_{\mathrm{BB}}$,

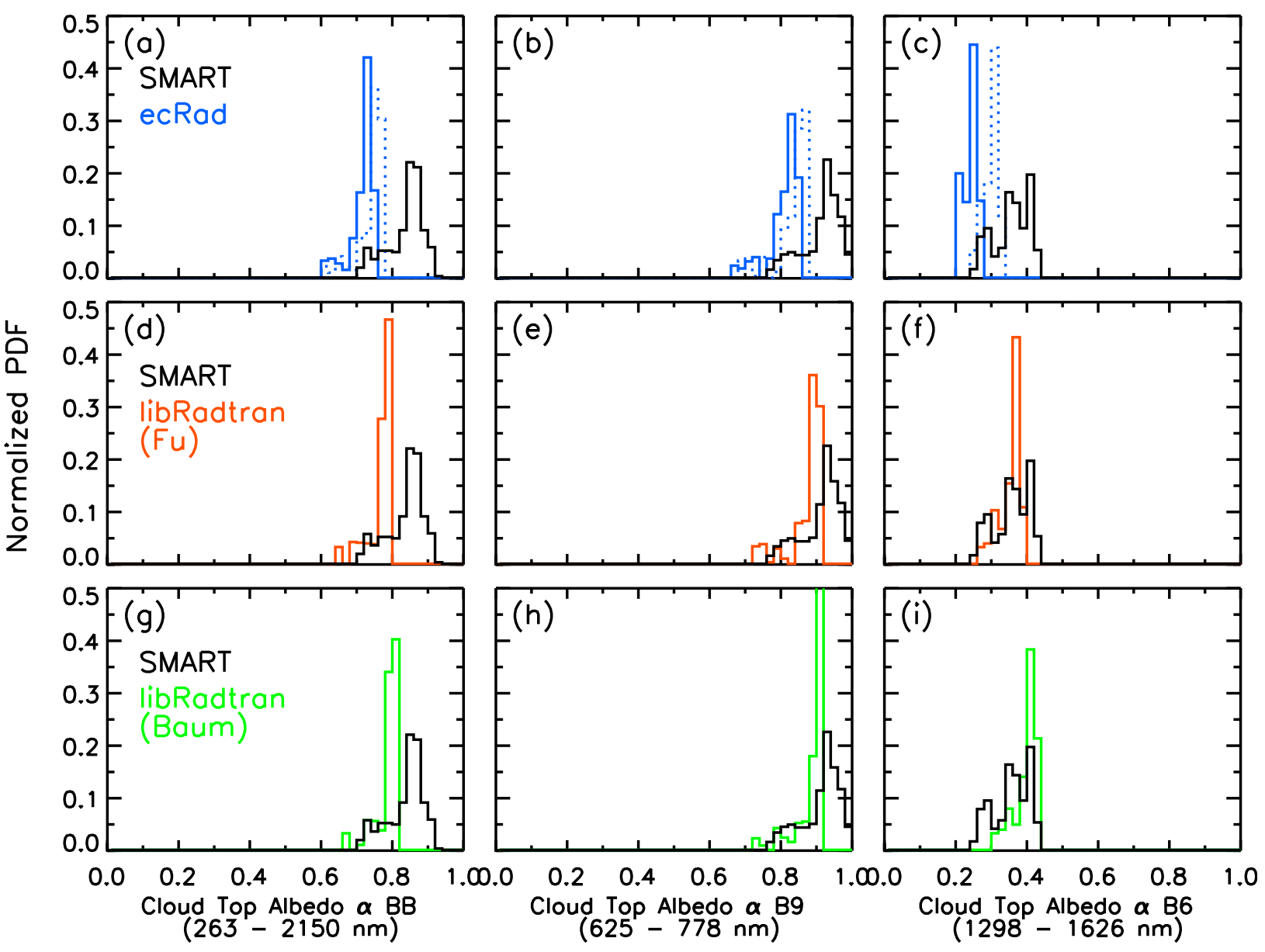

FIG. 7. PDFs of spectral and broadband cloud-top albedo $\alpha$ derived from SMART (black), ecRad Fu (blue), ecRad Yi (blue dotted), libRadtran Fu (orange), and libRadtran Baum (green) of cloud case 1. Solar zenith angle is $65.2^{\circ}$. 
TABLE 5. Mean, standard deviation, and median values of spectral irradiances $F^{\uparrow}$ and cloud-top albedo $\alpha$ for ice cloud case 1 (CC1).

\begin{tabular}{lcccccc}
\hline \hline & SMART & \multicolumn{2}{c}{ ecRad } & & \multicolumn{2}{c}{ libRadtran } \\
\cline { 3 - 4 } & & Fu & Yi & & Fu \\
\hline$F_{\mathrm{BB}}^{\uparrow}\left(\mathrm{W} \mathrm{m}^{-2}\right)$ & $428,40,435$ & $374,37,388$ & $387,38,402$ & & $413,37,428$ & $425,35,438$ \\
$F_{\mathrm{B} 9}^{\uparrow}\left(\mathrm{W} \mathrm{m}^{-2}\right)$ & $80,8,81$ & $72,8,74$ & $74,8,77$ & & $78,8,82$ & $7,8,82$ \\
$F_{\mathrm{B} 6}^{\uparrow}\left(\mathrm{W} \mathrm{m}^{-2}\right)$ & $17,2,16$ & $10,1,10$ & $13,1,13$ & & $15,1,15$ & $17,1,17$ \\
$\alpha_{\mathrm{BB}}$ & $0.84,0.05,0.85$ & $0.71,0.03,0.73$ & $0.74,0.04,0.75$ & & $0.77,0.05,0.79$ & $0.79,0.03,0.81$ \\
$\alpha_{\mathrm{B} 9}$ & $0.91,0.04,0.92$ & $0.81,0.04,0.83$ & $0.83,0.05,0.85$ & & $0.87,0.05,0.90$ & $0.89,0.04,0.91$ \\
$\alpha_{\mathrm{B} 6}$ & $0.36,0.05,0.36$ & $0.24,0.02,0.24$ & $0.29,0.02,0.30$ & & $0.35,0.03,0.36$ & $0.39,0.03,0.40$ \\
\hline
\end{tabular}

whereby $\alpha_{\mathrm{B} 9, \mathrm{lib}, \mathrm{Ba}}$ shows slightly higher values compared to $\alpha_{\mathrm{B} 9, \mathrm{eR}, \mathrm{Fu}}(+0.08)$ and $\alpha_{\mathrm{B} 9 \text {,lib,Fu }}(+0.06)$.

By contrast, significant differences appear for $\alpha_{\mathrm{B} 6}$ from the ecRad simulations. Cloud-top albedo $\alpha_{\mathrm{B} 6, \mathrm{eR}, \mathrm{Fu}}$ peaks at 0.25 and is lower by 0.11 compared to $\alpha_{\mathrm{B} 6, \mathrm{obs}}$, which has its maximum around 0.36. The Yi parameterization led to a median $\alpha_{\mathrm{B} 6, \mathrm{eR}, \mathrm{Yi}}$ of 0.29 , being closer to the observations and the libRadtran simulations. Calculated $\alpha_{\mathrm{B} 6 \text {,lib,Fu }}$ is shifted to lower values by 0.05 compared to $\alpha_{\mathrm{B} 6, \mathrm{obs}}$ and $\alpha_{\mathrm{B} 6 \text {,lib,Ba }}$ is slightly overestimating the observations of $\alpha_{\mathrm{B} 6, \mathrm{obs}}$. In spite of the significant relative difference in $\alpha_{\mathrm{B} 6}$, $F_{\mathrm{B} 6}^{\downarrow}$ of band 6 contributes to broadband $F_{\mathrm{BB}}^{\downarrow}$ and related $\alpha$ only to a minor fraction and, hence, the deviations in band 6 have reduced impact on the entire solar wavelength range.

By comparing simulated and observed upward irradiance, as well as $Z$, it is concluded that the IFS cloud scheme might not maintain sufficient amounts of cloud ice at CT, e.g., by rapid conversion of the cloud ice into larger snow particles by aggregation and growth at the expense of the smaller ice particles. As a result, the larger snow particles start to sediment and accumulate in lower cloud layers, leading to lower IWC at CT.

\section{b. Ice cloud case 2}

The second ice cloud case (CC2) between 1336 and 1358 UTC contains 660 simulation time steps and 2640 individual SMART measurements (Fig. 5). CC was observed when HALO crossed the WCB farther east, in the opposite flight direction of $\mathrm{CC} 1$ from northwest to southeast (see Fig. 1). The CTP is determined as ice all the time during $\mathrm{CC} 2$.

The time series of $F_{\mathrm{BB}}^{\uparrow}$ (Fig. 5a) and radar reflectivity (Fig. 5e) show an increased variability of cloud microphysical and macrophysical parameters, indicating that the eastern part of the WCB is more heterogeneously structured compared to the western part (CC1). Measured $F_{\mathrm{BB}, \mathrm{obs}}^{\uparrow}$ ranges from 500 to $620 \mathrm{~W} \mathrm{~m}^{-2}$, decreasing toward the end of the time series. Between 1336 and 1342 UTC, fluctuations in $F_{\text {obs }}^{\uparrow}$ are observed, but they are of reduced amplitude for the later part of the analyzed section. The fluctuations in
$F_{\text {obs }}^{\uparrow}$ could be attributed to intensive vertical mixing at CT by wind shear.

In general, the observed upward irradiance is systematically higher in all spectral bands compared to the models, leading to differences of up to approximately $100 \mathrm{~W} \mathrm{~m}^{-2}(16 \%)$ in $F_{\mathrm{BB}}^{\uparrow}$. In the first part of CC2 simulated $F_{\mathrm{BB}, \mathrm{lib}, \mathrm{Fu}}^{\uparrow}$ and $F_{\mathrm{BB}, \mathrm{lib}, \mathrm{Ba}}^{\uparrow}$ agree among each other but differences increase with time and peak around 1356 UTC with $\Delta F^{\uparrow} \approx 10 \mathrm{~W} \mathrm{~m}^{-2}$, when the cloud is getting optically thinner and the upward irradiance is lower. For clouds with decreasing cloud optical thickness $\tau$, single-scattering effects dominate and ice particle shape effects become more important (Wendisch et al. 2005). These shape effects are especially significant for the observed small particle size (see Fig. 2 and Wendisch et al. 2005). Further on, lower amounts of LWC and IWC are associated with smaller $r_{\text {eff }}$, leading to size dependent radiative effects between the different optical parameterizations, e.g., particle size dependence of $\tilde{\omega}$ (see Fig. 2). This implies that a correct crystal shape assumption and parameterization, capturing the natural appearance, becomes increasingly important for thin ice clouds.

Figures $5 c$ and $5 d$ show the time series of LWC and IWC, respectively. CC2 is dominated by the presence of ice but also contains small amounts of liquid water between 1336 and 1342 UTC at altitudes below $8000 \mathrm{~m}$, well below CT. In the same area of the vertical cross section elevated IWC is present, which is supported by the enhanced $Z_{\text {obs }}$ observed by HAMP (see Fig. 5e) and simulated by PAMTRA (see Fig. 5f). This supports the hypothesis of the underestimated LWC and IWC in the IFS AD. Despite the mismatch of LWC and IWC, differences between simulated and observed $Z$ arise from the radar-specific, size-dependent sensitivity, in particular for geometrically thin ice clouds. While large particles at cloud base dominate the measured signal, the small particles at CT are not detected and are responsible for the underestimation of $Z_{\mathrm{obs}}$ in the uppermost regions of the cloud.

PDFs of spectral cloud-top albedo $\alpha_{\lambda}$ for $\mathrm{CC} 2$ are presented in Figs. 8a-i. Mean and median values of 


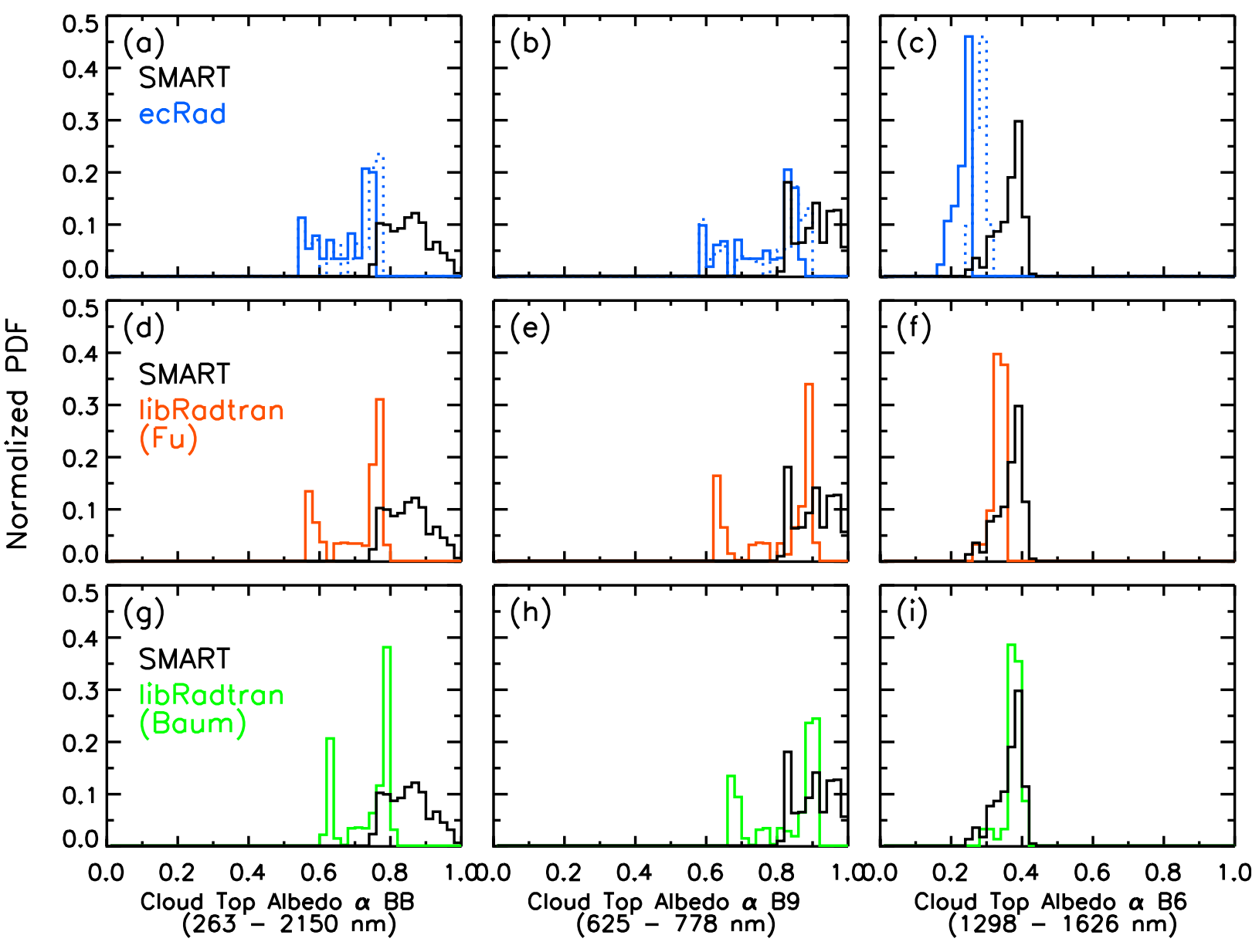

FIG. 8. PDFs of spectral and broadband cloud-top albedo $\alpha$ derived from SMART (black), ecRad Fu (blue), ecRad Yi (blue dotted), libRadtran $\mathrm{Fu}$ (orange), and libRadtran Baum (green) for cloud case 2. Solar zenith angle is 59.3.

simulated and observed upward irradiance, $\alpha$, and the macrophysical cloud and flight parameters are given in Table 6. The differences in broadband $\alpha_{\mathrm{BB}}$ and $\alpha_{\mathrm{B} 9}$ among the individual model runs of ecRad and libRadtran are small, typically below $\Delta \alpha=-0.06$. However, the same spectral features comparable to $\mathrm{CC} 1$ appear. All simulated $\alpha_{\mathrm{BB}}$ and $\alpha_{\mathrm{B} 9}$ are shifted to lower vales compared to the observations. The largest bias between $\alpha_{\mathrm{BB}, o b s}$ and simulated $\alpha_{\mathrm{BB}}$ is present for ecRad Yi $(\Delta \alpha=-0.12)$ and ecRad Fu $(\Delta \alpha=-0.16)$, followed by the libRadtran $\mathrm{Fu}$ $(\Delta \alpha=-0.08)$ and Baum parameterization $(\Delta \alpha=-0.06)$.

In contrast to $\mathrm{CC} 1$, the PDF of $\alpha_{\mathrm{B} 6, \mathrm{eR}, \mathrm{Fu}}$ for $\mathrm{CC} 2$ is shifted to higher cloud-top albedo compared to $\alpha_{\mathrm{B} 6 \text {,lib,Fu }}$ and followed by the libRadtran Baum parameterization. Cloud-top albedo $\alpha_{\mathrm{B} 6 \text {,lib,Ba }}$ agrees with the observations without any bias in the median, while $\alpha_{\mathrm{B} 6, \mathrm{lib}, \mathrm{Fu}}$ is shifted by $\Delta \alpha=-0.04$ with respect to $\alpha_{\mathrm{B} 6, \mathrm{obs}}$. Cloud-top albedo $\alpha_{\mathrm{B} 6 \mathrm{eR}, \mathrm{Fu}}$ is characterized by a median of 0.24 and a notable bias compared to the observations. The median of $\alpha_{\mathrm{B} 6, \mathrm{eR}, \mathrm{Yi}}$ is 0.28 with a smaller shift compared to the measurements. As with $\mathrm{CC} 1$, the best spectral representation of the ice clouds was achieved by the Yi ice optics parameterization (see Fig. 9).

\section{c. Spectral cloud-top albedo representation}

The homogeneity of the microphysical and macrophysical properties of $\mathrm{CC} 1$, as well as the relatively constant SZA, were appropriate to investigate the spectral representation of ice topped clouds in the models more explicitly. For that, all spectral bands of ecRad covered by SMART were utilized.

Differentiation by $\alpha_{\mathrm{B} 9}$ is regarded as a proxy for the cloud optical thickness or LWP and IWP, because $\tau$ is correlated to LWP of a cloud (Hansen and Travis 1974; Stephens 1978) and, in the two-stream approximation, $\alpha$ in the visible wavelength range can be approximated from $\tau$ (Bohren 1987). By binning the results by visible cloud-top albedo of ecRad band $9\left(\alpha_{\mathrm{B} 9}\right)$, where the singlescattering albedo is close to one and the relationship between $\tau$ and $\alpha$ is less dependent on the investigated 
TABLE 6. Mean, standard deviation, and median values of spectral irradiances $F^{\uparrow}$ and cloud-top albedo $\alpha$ of ice cloud case 2 (CC2).

\begin{tabular}{lcccccc}
\hline \hline & SMART & \multicolumn{2}{c}{ ecRad } & & \multicolumn{2}{c}{ libRadtran } \\
\cline { 3 - 4 } & & Fu & Yi & & Fu \\
\hline$F_{\mathrm{BB}}^{\uparrow}\left(\mathrm{W} \mathrm{m}^{-2}\right)$ & $545,48,541$ & $427,57,440$ & $440,63,464$ & & $464,63,503$ & Baum \\
$F_{\mathrm{B} 9}^{\uparrow}\left(\mathrm{W} \mathrm{m}^{-2}\right)$ & $102,10,101$ & $81,12,85$ & $84,14,89$ & & $88,14,96$ & $90,12,97,516$ \\
$F_{\mathrm{B} 6}^{\uparrow}\left(\mathrm{W} \mathrm{m}^{-2}\right)$ & $20,2,20$ & $11,1,12$ & $15,1,14$ & & $17,1,17$ & $20,1,20$ \\
$\alpha_{\mathrm{BB}}$ & $0.85,0.07,0.84$ & $0.66,0.07,0.68$ & $0.68,0.08,0.72$ & & $0.70,0.08,0.76$ & $0.73,0.07,0.78$ \\
$\alpha_{\mathrm{B} 9}$ & $0.92,0.09,0.92$ & $0.74,0.10,0.77$ & $0.76,0.11,0.81$ & & $0.79,0.11,0.87$ & $0.82,0.09,0.87$ \\
$\alpha_{\mathrm{B} 6}$ & $0.36,0.04,0.37$ & $0.22,0.02,0.24$ & $0.28,0.01,0.28$ & & $0.33,0.02,0.33$ & $0.37,0.02,0.38$ \\
\hline
\end{tabular}

parameterizations, potential differences between the simulated and observed spectral fluxes, due to errors in the IFS cloud fields, are removed. Furthermore, the single-scattering albedo is close to one in the visible and, hence, $\alpha$ does not saturate as $\tau$ increases, which it would in the near-infrared (Nakajima and King 1990). This makes the visible albedo a better proxy for $\tau$ than the near-infrared. Figures 9a-d show spectral $\alpha_{\lambda}$ separated for $\alpha_{\mathrm{B} 9}$ between 0.6 and 1.0 with bin sizes of $\Delta \alpha_{\mathrm{B} 9}=0.1$. The gray vertical lines mark the individual spectral bands of ecRad. The solid black lines represent the albedo measured by SMART, while the blue solid lines were calculated from ecRad Fu and the blue dotted lines represent the experimental ecRad Yi ice optics parameterization. Additionally, the libRadtran $\mathrm{Fu}$ (orange) and Baum (green) benchmark parameterizations were included.

For all simulated and observed $\alpha_{\lambda}$, a decrease with increasing wavelength is present. The characteristic spectral slope is declining for lower $\alpha_{\mathrm{B} 9}$ (analog lower $\tau$, LWC, and IWC) due to reduced IWC, larger $\tilde{\omega}$, and the growing influence of the underling sea surface.

For optically thick clouds, Fig. 9a shows identical spectral slopes for $\alpha_{\text {obs }}$ and $\alpha_{\mathrm{lib}, \mathrm{Ba}}$. In contrast, spectral differences among $\alpha_{\mathrm{eR}, \mathrm{Fu}}$ and $\alpha_{\mathrm{lib}, \mathrm{Fu}}$ for wavelength larger than $1400 \mathrm{~nm}$ are obvious. Smallest spectral $\alpha$ appear for $\alpha_{\mathrm{lib}, \mathrm{Fu}}$. The overestimation of $\alpha_{\mathrm{eR}, \mathrm{Fu}}$ is related to the spectral issue in the $\mathrm{Fu}$ ice optics parameterization, whereby for $\lambda<1500 \mathrm{~nm}$ all measured and simulated $\alpha_{\lambda}$ are almost matching.

For thinner clouds with $\alpha_{\mathrm{B} 9}$ between 0.8 and 0.9 , Fig. $9 \mathrm{~b}$ shows that for the entire wavelength range the simulated $\alpha_{\mathrm{eR}, \mathrm{Fu}}$ is lowest, followed by $\alpha_{\mathrm{eR}, \mathrm{Yi}}, \alpha_{\mathrm{obs}}$, $\alpha_{\mathrm{lib}, \mathrm{Fu}}$, and $\alpha_{\mathrm{lib}, \mathrm{Ba}}$ in increasing order. The largest differences among all simulations and observations appear for wavelength above $1500 \mathrm{~nm}$. By contrast, in Fig. 9c, with $\alpha_{\mathrm{B} 9}$ ranging between 0.7 and 0.8 , the observations mostly agree with $\alpha_{\mathrm{eR}, \mathrm{Fu}}$ and $\alpha_{\mathrm{lib} \text {,Fu }}$ for the entire wavelength range, whereby largest values appear for $\alpha_{\mathrm{lib}, \mathrm{Ba}}$ between 1000 and $1250 \mathrm{~nm}$ as well as between 1450 and $1750 \mathrm{~nm}$. In Fig. 9d, for the optically thinnest clouds, both ecRad simulations are almost identical and agree well with the measurements over the entire wavelength range, while the libRadtran simulations are systematically higher, between 1000 and $2000 \mathrm{~nm}$ wavelength.

The varying spectral slopes between the ice parameterizations within individual bins of $\alpha_{\mathrm{B} 9}$ are caused by the manifestation of the size- and wavelength-dependent single-scattering properties. With decreasing cloud optical thickness or $\alpha_{\mathrm{B} 9}$ the mean free pathlength of photons (the average distance between scattering events) increases, and hence the total number of scattering events decreases (Kokhanovsky 2004a,b). Therefore, the fraction of radiation undergoing single-scattering events, where ice crystal shape and size effects matter, in relation to the total observed reflected solar radiation increases. While ecRad applies bulk ice optical properties, the libRadtran Baum parameterization utilizes the full scattering phase functions of ice particles. In conjunction with the applied 16stream RTS in libRadtran, the influence of the single-scattering phase function, $r_{\text {eff }}$, and the SZA are more realistically represented, causing the differences in the spectral slopes. Nevertheless, the systematically higher spectral $\alpha$ by libRadtran Baum compared to all ecRad simulations and the observation might be caused by the selected ice particle shape "general habit mixture" (GHM) and its composition, which might deviate from reality.

To estimate the spectral sensitivity of upward irradiance and $\alpha$ to IWC and $r_{\text {eff }}$ for cloud ice and snow particles, a total number of 81 simulations for combinations of IWC and $r_{\text {eff }}$ were simulated with libRadtran. The simulations utilized the Baum GHM ice optics parameterization. The geometrical thickness of the ice cloud is one kilometer, the IWC was varied from 0.04 to $0.40 \mathrm{~g} \mathrm{~m}^{-3}$, and $r_{\text {eff }}$ from $10 \mu \mathrm{m}$, representative for cloud ice, to $50 \mu \mathrm{m}$, representing snow particles (maximum particle size, that can be simulated with libRadtran).

For four selected cloud combinations, representing the boundaries of the simulated grid, the relative changes in upward irradiance with respect to the maximum value of $F^{\uparrow}$ of the simulated cloud cases are calculated. By increasing $r_{\text {eff }}$ from 10 to $50 \mu \mathrm{m}$ for 

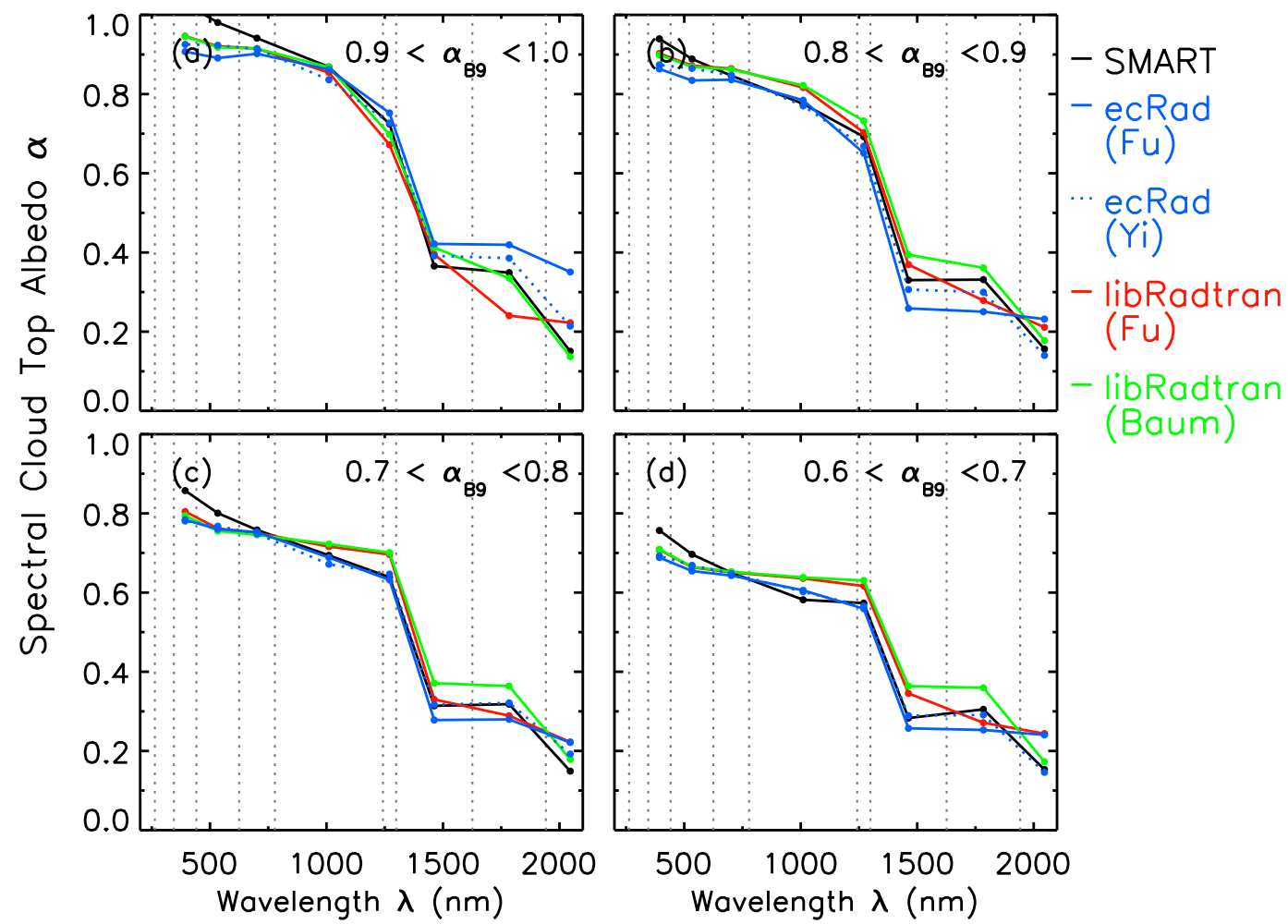

FIG. 9. Spectral cloud-top albedo $\alpha$ of SMART (black), ecRad Fu (solid blue), ecRad Yi (dotted blue), libRadtran Fu (solid orange), and libRadtran Baum (solid green) binned for $\alpha_{\mathrm{B} 9}$. Each point of the functions represents the discrete band average, connected for better legibility.

constant IWC of $0.04 \mathrm{~g} \mathrm{~m}^{-3}$, fewer but larger particles were simulated, which results in a decrease in $F^{\uparrow}$ by $35 \%$. Similar, by increasing $r_{\text {eff }}$ from 10 to $50 \mu \mathrm{m}$ for constant IWC of $0.40 \mathrm{~g} \mathrm{~m}^{-3}$ a decrease in $F^{\uparrow}$ by $25 \%$ is reported. By contrast, an increase in IWC from 0.04 to $0.40 \mathrm{~g} \mathrm{~m}^{-3}$ leads to an increase in $F^{\uparrow}$ of $30 \%$ and $40 \%$ for $r_{\text {eff }}$ of 10 and $50 \mu \mathrm{m}$, respectively. For all other simulated combinations of IWC and $r_{\text {eff }}$ no clear conclusion can be drawn, as the simulated $F^{\uparrow}$ is not independent from $r_{\text {eff }}$ and IWC. From the sensitivity study it can be concluded that the absolute and relative intensity of $F^{\uparrow}$, as well its spectral slope, is in the same range or slightly more influenced by the $r_{\text {eff }}$ than IWC, in particular for thin clouds with low IWC and for wavelengths larger than $1200 \mathrm{~nm}$. As a result, the observed differences in $F^{\uparrow}$ for ecRad band 6 can be partly related to spectral feature in the single-scattering phase function of the Fu ice optics parameterization.

\section{d. Boundary layer cloud case}

To investigate the representation of BLC in the IFS $\mathrm{AD}$ and the ecRad simulations, a characteristic flight section between 1300 and 1340 UTC was selected, labeled as CC3 (Fig. 5). The flight section between the two WCB crossings (1215-1340 UTC) is characterized by heterogeneous liquid water clouds. For these pure liquid water clouds, the ice optics parameterization is irrelevant and the default parameterization by $\mathrm{Fu}$ was selected in ecRad.

For CC3, the simulated $F_{\mathrm{BB}}^{\uparrow}$ by ecRad and libRadtran (benchmark) are systematically lower compared to the observations, clearly visible in the time series of Fig. 5 b. For specific periods, e.g., around 1310 UTC, the relative differences between the models and $F_{\mathrm{BB}, \mathrm{obs}}^{\uparrow}$ are up to $47 \%$.

PDFs of broadband and spectral $\alpha$ from the BLC case are given in Figs. 10a-i. In Table 7 the mean and median values of broadband and spectral $F^{\uparrow}$ and $\alpha$ are given. In general, the PDFs of simulated $\alpha_{\mathrm{BB}}$ are broad and shifted toward lower values by approximately 0.13 compared to $\alpha_{\mathrm{BB}, \text { obs }}$. The distributions of $\alpha$ by the models are characterized by bimodal (B6) or trimodal distributions (BB and B9). The lowest peak is caused by cloud-free model columns and determined by the sea surface albedo. The other two peaks are related to individual cloud cells (second mode) and to more aggregated cloud fields (third mode). By contrast, the PDFs of $\alpha_{\text {obs }}$ are characterized by monomodal (B6) and bimodal (BB and B9) distributions, always missing the lowest peak. The absence of the lowest mode is related to two effects: (i) While the ICA simulations provide irradiances for 

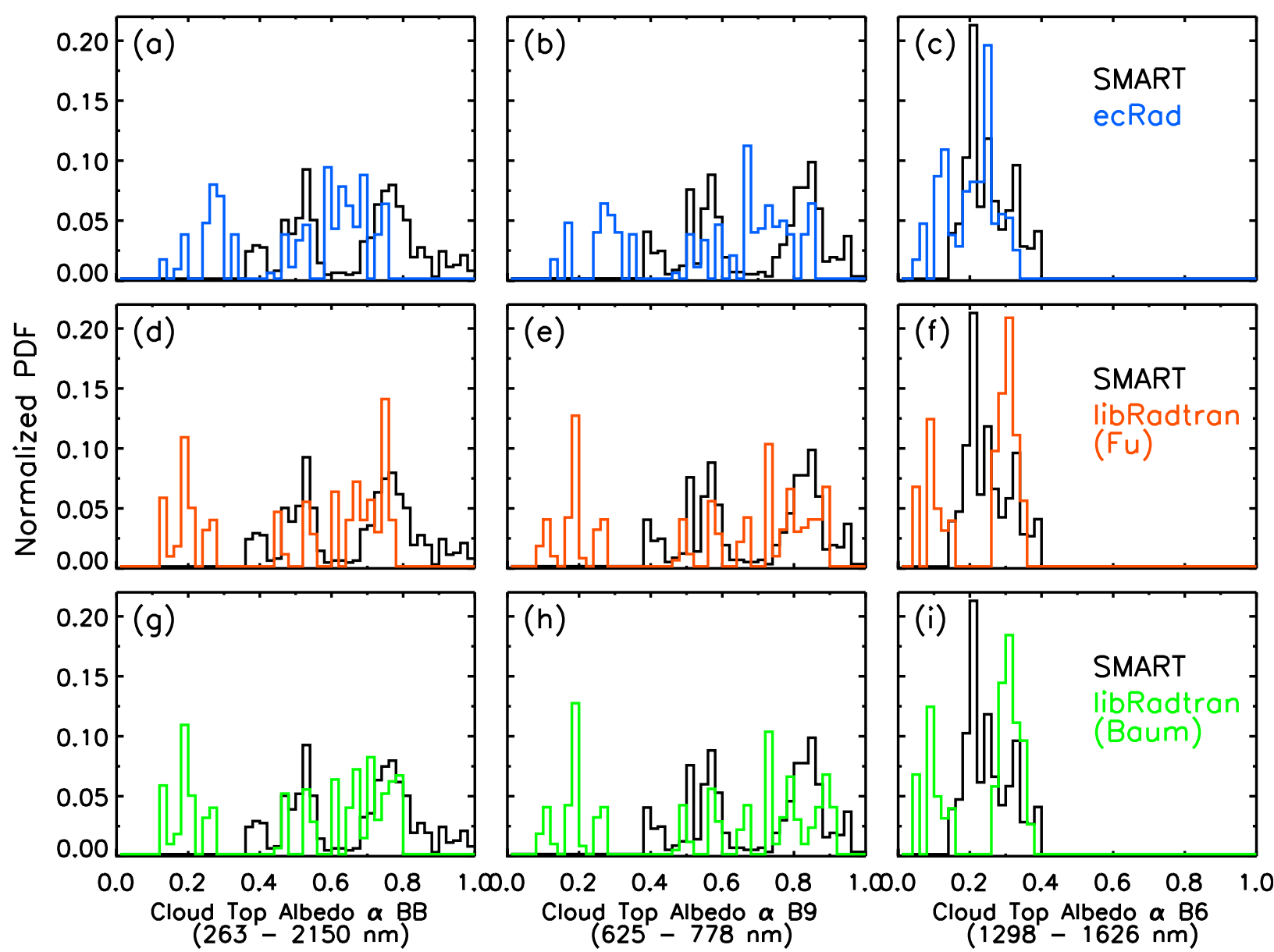

FIG. 10. PDFs of spectral and broadband cloud-top albedo $\alpha$ derived from SMART (black), ecRad Fu (blue), libRadtran Fu (orange), and libRadtran Baum (green) for cloud case 3.

individual columns (in extreme events cloud free), the observed $F^{\uparrow}$ by SMART are composed by cloud covered and cloud-free regions, smoothing the lowest peak. (ii) The low values in simulated $F^{\uparrow}$ further indicate that the models have simulated less cloud-containing model columns compared to the observations.

The number of cloud-free columns in the simulations bias the mean and median values of $\alpha$ toward smaller values. However, comparing only the second and third mode of the distributions, a good agreement was found. While $a_{\mathrm{BB}, \mathrm{eR}}$ is shifted to lower values by approximately -0.03 , the libRadtran Fu and Baum parameterization match with SMART. An exception appears for B6 where the second mode (individual clouds) of ecRad agrees with the measurements, whereby libRadtran $\mathrm{Fu}$ and Baum overestimate $\alpha_{\mathrm{B} 6 \text {,obs }}$ from SMART by up to 0.1 . One potential reason is the lower $r_{\text {eff }}$ parameterized from the IFS AD, which increases $\alpha$ in the scattering wavelength bands and reduces $\alpha$ in the absorption wavelength bands.
From CC3 it is concluded that BLC are not well represented in the IFS AD by LWC and $f$, leading to cloud-free model grid boxes and to a systematic underestimation of $F^{\uparrow}$ and $\alpha$ for regions, where optically thin clouds are diagnosed. Both models are not able to correctly simulate the observed $F^{\uparrow}$. The spectrally independent disparity, given by the same PDF distributions of $\alpha$ from ecRad and libRadtran for band 9 (Figs. 10b,e) as well as band 6 (Figs. 10c,f) indicates a biased cloud representation in the IFS $\mathrm{AD}$ by the total cloud cover $f$, as it scales simulated $F$ and $\alpha$ proportionally. In contrast, misrepresentation in LWC or $r_{\text {eff }}$ would dominate the scattering or absorbing wavelength band, respectively, leading to spectral differences.

Due to the small number of cloud samples within this selected section, the representation is limited. No significant differences between ecRad and libRadtran were found, indicating that the observed low level liquid water clouds are sufficiently represented by the RTS. 
TABLE 7. Mean, standard deviation, and median values of spectral irradiances $F^{\uparrow}$ and cloud-top albedo $\alpha$ of the boundary layer cloud section CC3.

\begin{tabular}{lcccc}
\hline \hline & SMART & ecRad & libRadtran \\
\cline { 3 - 4 } & & Fu & Fu & Baum \\
\hline$F_{\mathrm{BB}}^{\uparrow}\left(\mathrm{W} \mathrm{m}^{-2}\right)$ & $453,106,485$ & $345,124,402$ & $351,159,425$ & $354,162,427$ \\
$F_{\mathrm{B} 9}^{\uparrow}\left(\mathrm{W} \mathrm{m}^{-2}\right)$ & $84,21,91$ & $64,25,77$ & $64,32,77$ & $64,32,77$ \\
$F_{\mathrm{B} 6}^{\uparrow}\left(\mathrm{W} \mathrm{m}^{-2}\right)$ & $15,4,14$ & $11,4,12$ & $13,6,16$ & $13,6,16$ \\
$\alpha_{\mathrm{BB}}$ & $0.66,0.16,0.71$ & $0.51,0.19,0.59$ & $0.50,0.23,0.60$ & $0.50,0.24,0.60$ \\
$\alpha_{\mathrm{B} 9}$ & $0.72,0.28,0.78$ & $0.55,0.22,0.66$ & $0.54,0.28,0.65$ & $0.55,0.28,0.65$ \\
$\alpha_{\mathrm{B} 6}$ & $0.25,0.06,0.24$ & $0.20,0.07,0.21$ & $0.23,0.10,0.28$ & $0.23,0.11,0.29$ \\
\hline
\end{tabular}

\section{Conclusions}

In this paper a novel method was presented to compare airborne observations of spectral upward and downward irradiances observed by the Spectral Modular Airborne Radiation Measurement System (SMART) on board the High Altitude and Long Range Research Aircraft (HALO) with along-track radiative transfer simulations (RTS). The RTS were performed with the radiation module ecRad of the Integrated Forecast System (IFS), operated by the European Centre for Medium-Range Weather Forecasts (ECMWF), and the library for Radiative transfer (libRadtran) based on hourly $0.1^{\circ}$ IFS analysis data (IFS AD). Utilizing two different RTS, initialized with the same IFS AD, differences between simulated and observed irradiances were decomposed into inaccurate cloud optics parameterizations and/or shortcomings within the IFS AD with respect to cloud representation. The spatial and temporal resolution of the IFS AD was sufficient to be compared with spatially averaged airborne measurements of irradiance and allowed for a statistical model evaluation. Nevertheless, the availability of higher resolution analysis fields would enable the investigation of small-scale effects below the currently available resolution of $8 \mathrm{~km}$, e.g., for the investigation of stratocumulus cloud fields.

For the analyzed research flight (RF04), performed on 26 October 2016 during the North Atlantic Waveguide and Downstream Impact Experiment (NAWDEX; Schäfler et al.2018) campaign, it was found that the IFS AD and the RTS were generally able to reproduce the observed radiation field above the clouds. The limited area covered by the airborne observations during RF04 meant that a statistical analysis was required to be representative for a larger domain. That way, each measurement and related simulation is regarded as a random sample of a whole population. Using independent, individual measurement points enabled to statistically probe and compare the radiation field and, hence, the overall performance of the ecRad model. In addition, the sampling of representative cloud sections allowed to investigate cloud optics parameterization as a function of the cloud microphysical and macrophysical properties of particular cloud types.

Due to the limited sampling time and ambiguity of the cloud macrophysical parameters, the comparison of measured and simulated irradiances, by two independent models, did not allow to explicitly distinguish between errors caused by the IFS AD or the RTS. Hence, the following two statements concerning the cloud representation in the IFS AD can be regarded as preliminary indications only:

(i) Upward irradiance and cloud-top albedo of heterogeneously distributed boundary layer clouds (BLC) is underestimated due to biased liquid water content LWC and total cloud cover in the IFS AD, which could be related to the coarse vertical model resolution and small-scale turbulent mixing processes.

(ii) Cloud ice amount and ice particle radius are underestimated at cloud top, possibly due to the conversion of cloud ice into snow particles and their sedimentation.

The application of the independent column approximation (ICA), which does not consider photon transport through the model column sides, may lead to discrepancies between the simulations and the observations. The ICA becomes unsuitable with increasing cloud field heterogeneity, e.g., for low-level liquid water clouds with total cloud cover of less than $50 \%$. In spite of that, in regions, where the total cloud cover is below $50 \%$, the systematically lower measured broadband and spectral $F^{\uparrow}$ compared to the simulations is attributed to the applied cloud overlap assumption.

To fully clarify the aforementioned statements further investigation is required. In situ measurements would be beneficial to obtain a more comprehensive cloud perspective, not being provided by observations of irradiances and remote sensing alone.

Nevertheless, by binning the observed and simulated datasets by the spectral cloud-top albedo $\alpha$ (Fig. 9), the 
errors, which solely stem from the ice optics parameterization, were separated and led to the following conclusions:

(i) The spectral resolution of the Fu ice optics parameterization in ecRad is not capable of representing the ice absorption features of the single-scattering albedo $\tilde{\omega}$ around 1200 and $1400 \mathrm{~nm}$ wavelength, causing a significant underestimation in spectral $F^{\uparrow}$ for the covered spectral band between 1298 and $1626 \mathrm{~nm}$ of up to $27 \%$. For broadband $F^{\uparrow}$ of the integrated solar wavelength $(263-2150 \mathrm{~nm})$ the deviations are up to $4 \%$.

(ii) The Yi ice optics parameterizations causes a larger underestimation in broadband $F^{\uparrow}$ and $\alpha$ of up to $8 \%$ compared to ecRad Fu and libRadtran Baum simulations, but captures the spectral response of the single-scattering albedo better.

Therefore, it is further considered to validate the ecRad Yi ice optics parameterization with respect to the broadband upward irradiance. This requires the reconsideration of the spectral mass extinction, the singlescattering albedo, and the asymmetry coefficients, which convert the cloud microphysical properties into cloud optical properties. The adaption of the coefficients has to consider for the spectral representation of ice crystals but also has to ensure that the local and global radiative balance is maintained (Yi et al. 2013). Hence, additional evaluation is required for an extended range of solar zenith angles and environmental conditions, e.g., other flights and campaigns, covering different regions of Earth.

The presented method is potentially suited to be applied to further flights of NAWDEX to increase the statistical significance of the cloud statistics. Further on, research flights of the Arctic Cloud Observations Using Airborne Measurements during Polar Day (ACLOUD) campaign 2017, which is part of the Arctic Amplification: Climate Relevant Atmospheric and Surface Processes, and Feedback Mechanisms [(AC $)^{3}$ ] campaign framework (Wendisch et al. 2019), will allow the radiative representation of mixed-phase clouds in the Arctic to be investigated. Furthermore, analyzing flights of the Elucidating the Role of Clouds-Circulation Coupling in Climate (EUREC4A; Bony et al. (2017)) campaign enables to verify the capability of IFS and ecRad to simulated subtropical cloud regimes.

Acknowledgments. This research was funded by the German Research Foundation (DFG; HALO-SPP 1294). The authors acknowledge the support by the Deutsche Forschungsgemeinschaft (DFG) through Grants CR 111/10-1, PF 384/7-1/2, PF 384/16-1, and WE 1900/35-1, as well as the Max Planck Society and the German Aerospace Center (DLR). Special thanks goes to Heini Wernli, who provided the IFS analysis data, and Felix Ament and Heike Konow, who contributed the calibrated HALO Microwave Package (HAMP) radar and microwave data. Fruitful and inspiring discussions with Maike Ahlgrimm, Richard Forbes, and Alessio Bozzo from the European Centre for Medium-Range Forecasts (ECWMF) helped and improved the paper manuscript significantly. Additionally, the authors thank the pilots and appreciate the support by the Flugbereitschaft of DLR, and enviscope $\mathrm{GmbH}$ for preparation and testing of SMART.

\section{REFERENCES}

Ahlgrimm, M., and M. Köhler, 2010: Evaluation of trade cumulus in the ECMWF model with observations from CALIPSO. Mon. Wea. Rev., 138, 3071-3083, https://doi.org/10.1175/ 2010MWR3320.1.

_ , and R. Forbes, 2012: The impact of low clouds on surface shortwave radiation in the ECMWF model. Mon. Wea. Rev., 140, 3783-3794, https://doi.org/10.1175/MWR-D-11-00316.1.

Bauer, P., A. Thorpe, and G. Brunet, 2015: The quiet revolution of numerical weather prediction. Nature, 525, 47-55, https:// doi.org/10.1038/nature14956.

Baum, B. A., A. J. Heymsfield, P. Yang, and S. T. Bedka, 2005a: Bulk scattering properties for the remote sensing of ice clouds. Part I: Microphysical data and models. J. Appl. Meteor., 44, 1885-1895, https://doi.org/10.1175/JAM2308.1.

_, P. Yang, A. J. Heymsfield, S. Platnick, M. D. King, Y. X. $\mathrm{Hu}$, and S. T. Bedka, 2005b: Bulk scattering properties for the remote sensing of ice clouds. Part II: Narrowband models. J. Appl. Meteor., 44, 1896-1911, https://doi.org/10.1175/ JAM2309.1.

,-- S. Nasiri, A. K. Heidinger, A. Heymsfield, and J. Li, 2007: Bulk scattering properties for the remote sensing of ice clouds. Part III: High-resolution spectral models from 100 to $3250 \mathrm{~cm}^{-1}$. J. Appl. Meteor. Climatol., 46, 423-434, https:// doi.org/10.1175/JAM2473.1.

Beesley, J. A., C. S. Bretherton, C. Jakob, E. L. Andreas, J. M. Intrieri, and T. A. Uttal, 2000: A comparison of cloud and boundary layer variables in the ECMWF forecast model with observations at Surface Heat Budget of the Arctic Ocean (SHEBA) ice camp. J. Geophys. Res., 105, 12 337-12349, https://doi.org/10.1029/2000JD900079.

Beljaars, A., and Coauthors, 2018: The numerics of physical parametrization in the ECMWF model. Front. Earth Sci., 6, 137, https://doi.org/10.3389/feart.2018.00137.

Bierwirth, E., and Coauthors, 2013: Optical thickness and effective radius of Arctic boundary-layer clouds retrieved from airborne nadir and imaging spectrometry. Atmos. Meas. Tech., 6 , 1189-1200, https://doi.org/10.5194/amt-6-1189-2013.

Bodhaine, B., N. Wood, E. Dutton, and J. Slusser, 1999: On Rayleigh optical depth calculations. J. Atmos. Oceanic Technol., 16, 1854-1861, https://doi.org/10.1175/1520-0426(1999) 016<1854:ORODC >2.0.CO;2.

Bohren, C. F., 1987: Multiple-Scattering of light and some of its observable consequences. Amer. J. Phys., 55, 524-533, https:// doi.org/10.1119/1.15109. 
Bony, S., and Coauthors, 2017: EUREC4A: A field campaign to elucidate the couplings between clouds, convection and circulation. Surv. Geophys., 38, 1529-1568, https://doi.org/10.1007/ s10712-017-9428-0.

Cahalan, R., 1994: Bounded cascade clouds: Albedo and effective thickness. Nonlinear Processes Geophys., 1, 156-167, https:// doi.org/10.5194/npg-1-156-1994.

Cazenave, Q., M. Ceccaldi, J. Delanoë, J. Pelon, S. Groß, and A. Heymsfield, 2019: Evolution of DARDAR-CLOUD ice cloud retrievals: New parameters and impacts on the retrieved microphysical properties. Atmos. Meas. Tech., 12, 2819-2835, https://doi.org/10.5194/amt-12-2819-2019.

Di Michele, S., M. Ahlgrimm, R. Forbes, M. Kulie, R. Bennartz, M. Janisková, and P. Bauer, 2012: Interpreting an evaluation of the ECMWF global model with CloudSat observations: Ambiguities due to radar reflectivity forward operator uncertainties. Quart. J. Roy. Meteor. Soc., 138, 2047-2065, https:// doi.org/10.1002/qj.1936.

Edwards, J. M., and A. Slingo, 1996: Studies with a flexible new radiation code. I: Choosing a configuration for a large-scale model. Quart. J. Roy. Meteor. Soc., 122, 689-719, https:// doi.org/10.1002/qj.49712253107.

Emde, C., and Coauthors, 2016: The libRadtran software package for radiative transfer calculations (version 2.0.1). Geosci. Model Dev., 9, 1647-1672, https://doi.org/10.5194/gmd-9-1647-2016.

Ewald, F., T. Kölling, A. Baumgartner, T. Zinner, and B. Mayer, 2016: Design and characterization of specMACS, a multipurpose hyperspectral cloud and sky imager. Atmos. Meas. Tech., 9, 2015-2042, https://doi.org/10.5194/amt-9-2015-2016.

_ , S. Groß, M. Hagen, L. Hirsch, J. Delanoë, and M. BauerPfundstein, 2019: Calibration of a $35 \mathrm{GHz}$ airborne cloud radar: Lessons learned and intercomparisons with $94 \mathrm{GHz}$ cloud radars. Atmos. Meas. Tech., 12, 1815-1839, https://doi.org/ 10.5194/amt-12-1815-2019.

Field, P. R., A. J. Heymsfield, and A. Bansemer, 2007: Snow size distribution parameterization for midlatitude and tropical ice clouds. J. Atmos. Sci., 64, 4346-4365, https://doi.org/10.1175/ 2007JAS2344.1.

Forbes, R. M., and M. Ahlgrimm, 2014: On the representation of highlatitude boundary layer mixed-phase cloud in the ECMWF global model. Mon. Wea. Rev., 142, 3425-3445, https://doi.org/10.1175/ MWR-D-13-00325.1.

Fu, Q., 1996: An accurate parameterization of the solar radiative properties of cirrus clouds in climate models. J. Climate, $\mathbf{9}$, 2058-2082, https://doi.org/10.1175/1520-0442(1996)009<2058: AAPOTS $>2.0 . C O ; 2$.

- 2007: A new parameterization of an asymmetry factor of cirrus clouds for climate models. J. Atmos. Sci., 64, 4140-4150, https://doi.org/10.1175/2007JAS2289.1.

_, P. Yang, and W. Sun, 1998: An accurate parameterization of the infrared radiative properties of cirrus clouds in climate models. J. Climate, 11, 2223-2237, https://doi.org/10.1175/ 1520-0442(1998)011<2223:AAPOTI>2.0.CO;2.

Gayet, J. F., and Coauthors, 2002: Quantitative measurement of the microphysical and optical properties of cirrus clouds with four different in situ probes: Evidence of small ice crystals. Geophys. Res. Lett., 29, 2230, https://doi.org/10.1029/2001GL014342.

Hansen, J. E., and L. D. Travis, 1974: Light scattering in planetary atmospheres. Space Sci. Rev., 16, 527-610, https://doi.org/ 10.1007/BF00168069.

Hogan, R. J., and A. Bozzo, 2018: A flexible and efficient radiation scheme for the ECMWF model. J. Adv. Model. Earth Syst., 10, 1990-2008, https://doi.org/10.1029/2018MS001364.
_, R. Honeyager, J. Tyynelä, and S. Kneifel, 2017: Calculating the millimetre-wave scattering phase function of snowflakes using the self-similar Rayleigh-Gans approximation. Quart. J. Roy. Meteor. Soc., 143, 834-844, https://doi.org/10.1002/qj.2968.

Jacob, D. J., and Coauthors, 2010: The Arctic Research of the Composition of the Troposphere from Aircraft and Satellites (ARCTAS) mission: Design, execution, and first results. Atmos. Chem. Phys., 10, 5191-5212, https://doi.org/10.5194/ acp-10-5191-2010.

Jäkel, E., J. Walther, and M. Wendisch, 2013: Thermodynamic phase retrieval of convective clouds: Impact of sensor viewing geometry and vertical distribution of cloud properties. Atmos. Meas. Tech., 6, 539-547, https://doi.org/10.5194/amt-6-539-2013.

Joseph, J. H., W. J. Wiscombe, and J. A. Weinman, 1976: The deltaEddington approximation for radiative flux transfer. J. Atmos. Sci., 33, 2452-2459, https://doi.org/10.1175/1520-0469(1976) $033<2452$ :TDEAFR $>2.0 . \mathrm{CO} ; 2$.

Kokhanovsky, A. A., 2004a: Optical properties of terrestrial clouds. Earth-Sci. Rev., 64, 189-241, https://doi.org/10.1016/ S0012-8252(03)00042-4.

, 2004b: The depth of sunlight penetration in cloud fields for remote sensing. IEEE Geosci. Remote Sens. Lett., 1, 242-245, https://doi.org/10.1109/LGRS.2004.832228.

Korolev, A. V., E. F. Emery, J. W. Strapp, S. G. Cober, and G. A. Isaac, 2013: Quantification of the effects of shattering on airborne ice particle measurements. J. Atmos. Oceanic Technol., 30, 2527-2553, https://doi.org/10.1175/JTECH-D-13-00115.1.

Krämer, M., and Coauthors, 2016: A microphysics guide to cirrus clouds-Part 1: Cirrus types. Atmos. Chem. Phys., 16, 3463-3483, https://doi.org/10.5194/acp-16-3463-2016.

Krisna, T. C., and Coauthors, 2018: Comparing airborne and satellite retrievals of cloud optical thickness and particle effective radius using a spectral radiance ratio technique: Two case studies for cirrus and deep convective clouds. Atmos. Chem. Phys., 18, 4439-4462, https://doi.org/10.5194/acp-18-4439-2018.

Kurucz, R., 1992: Synthetic infrared spectra. Proc. 154th Symp., Tucson, AZ, International Astronomical Union, 523-531.

Liljegren, J. C., S. A. Boukabara, K. Cady-Pereira, and S. A. Clough, 2005: The effect of the half-width of the 22-GHz water vapor line on retrievals of temperature and water vapor profiles with a 12-channel microwave radiometer. IEEE Trans. Geosci. Remote Sens., 43, 1102-1108, https://doi.org/10.1109/ TGRS.2004.839593.

Liou, K.-N., 1986: Influence of cirrus clouds on weather and climate processes: A global perspective. Mon. Wea. Rev., 114, 1167-1199, https://doi.org/10.1175/1520-0493(1986)114<1167: IOCCOW $>2.0 . \mathrm{CO} ; 2$.

Luebke, A. E., and Coauthors, 2016: The origin of midlatitude ice clouds and the resulting influence on their microphysical properties. Atmos. Chem. Phys., 16, 5793-5809, https://doi.org/ 10.5194/acp-16-5793-2016.

Marshak, A., A. Davis, W. Wiscombe, and G. Titov, 1995: The verisimilitude of the independent pixel approximation used in cloud remote sensing. Remote Sens. Environ., 52, 71-78, https://doi.org/10.1016/0034-4257(95)00016-T.

Martin, G. M., D. W. Johnson, and A. Spice, 1994: The measurement and parameterization of effective radius of droplets in warm stratocumulus clouds. J. Atmos. Sci., 51, 1823-1842, https://doi.org/10.1175/1520-0469(1994)051<1823:TMAPOE > 2.0.CO;2.

Mech, M., E. Orlandi, S. Crewell, F. Ament, L. Hirsch, M. Hagen, G. Peters, and B. Stevens, 2014: HAMP-The microwave package on the High Altitude and Long Range Research 
Aircraft (HALO). Atmos. Meas. Tech., 7, 4539-4553, https:// doi.org/10.5194/amt-7-4539-2014.

—_, M. Maahn, S. Kneifel, D. Ori, E. Orlandi, P. Kollias, V. Schemann, and S. Crewell, 2020: PAMTRA 1.0: A Passive and Active Microwave Radiative Transfer tool for simulating radiometer and radar measurements of the cloudy atmosphere. Geosci. Model Dev., https://doi.org/ 10.5194/gmd-2019-356, in press.

Mie, G., 1908: Beiträge zur Optik trüber Medien, speziell kolloidaler Metallösungen. Ann. Phys., 25, 377-445, https:// doi.org/10.1002/ANDP.19083300302.

Mishchenko, M., and L. Travis, 1994: T-matrix computations of light scattering by large spheroidal particles. Opt. Commun., 109, 16-21, https://doi.org/10.1016/0030-4018(94)90731-5.

Mitchell, D. L., R. P. d'Entremont, and R. P. Lawson, 2010: Inferring cirrus size distributions through satellite remote sensing and microphysical databases. J. Atmos. Sci., 67, 1106-1125, https://doi.org/10.1175/2009JAS3150.1.

Mlawer, E., S. Taubman, P. Brown, M. Iacono, and S. Clough, 1997: Radiative transfer for inhomogeneous atmospheres: RRTM, a validated correlated-k model for the longwave. J. Geophys. Res., 102, 16 663-16 682, https://doi.org/10.1029/97JD00237.

Morcrette, J.-J., G. Mozdzynski, and M. Leutbecher, 2008: A reduced radiation grid for the ECMWF Integrated Forecasting System. Mon. Wea. Rev., 136, 4760-4772, https://doi.org/ 10.1175/2008MWR2590.1.

Nakajima, T., and M. D. King, 1990: Determination of the optical thickness and effective particle radius of clouds from reflected solar radiation measurements. Part I: Theory. J. Atmos. Sci., 47, 1878-1893, https://doi.org/10.1175/15200469(1990)047<1878:DOTOTA > 2.0.CO;2.

Platnick, S., and Coauthors, 2013: Assessment of IDPS VIIRS cloud products and recommendations for EOS-era cloud climate data record continuity. NASA Goddard Space Flight Center Tech. Rep., 57 pp.

Rosenkranz, P. W., 2015: A model for the complex dielectric constant of supercooled liquid water at microwave frequencies. IEEE Trans. Geosci. Remote Sens., 53, 1387-1393, https:// doi.org/10.1109/TGRS.2014.2339015.

Schäfler, A., and Coauthors, 2018: The North Atlantic Waveguide and Downstream Impact Experiment. Bull. Amer. Meteor. Soc., 99, 1607-1637, https://doi.org/10.1175/BAMS-D-17-0003.1.

Shonk, J. K. P., and R. J. Hogan, 2008: Tripleclouds: An efficient method for representing cloud inhomogeneity in $1 \mathrm{~d}$ radiation schemes by using three regions at each height. J. Climate, 21, 2352-2370, https://doi.org/10.1175/2007JCLI1940.1.

Smith, W. M., and Coauthors, 2017: Arctic Radiation-IceBridge Sea and Ice Experiment (ARISE): The Arctic radiant energy system during the critical seasonal ice transition. Bull. Amer. Meteor. Soc., 98, 1399-1426, https://doi.org/10.1175/ BAMS-D-14-00277.1.

Stamnes, K., S.-C. Tsay, W. Wiscombe, and I. Laszlo, 2000: DISORT, a general-purpose Fortran program for discreteordinate-method radiative transfer in scattering and emitting layered media: Documentation of methodology. Stevens Institute of Technology Dept. of Physics and Engineering Physics Tech. Rep., 112 pp.

Stephens, G. L., 1978: Radiation profiles in extended water clouds. II: Parameterization schemes. J. Atmos. Sci., 35, 2123-2132, https://doi.org/10.1175/1520-0469(1978)035<2123:RPIEWC> 2.0.CO;2.

Stevens, B., and S. Bony, 2013: What are climate models missing? Science, 340, 1053-1054, https://doi.org/10.1126/science.1237554.
— - and Coauthors, 2019: A high-altitude long-range aircraft configured as a cloud observatory: The NARVAL expeditions. Bull. Amer. Meteor. Soc., 100, 1061-1077, https:// doi.org/10.1175/BAMS-D-18-0198.1.

Sun, W., and Q. Fu, 2001: Anomalous diffraction theory for randomly oriented nonspherical particles: A comparison between original and simplified solutions. J. Quant. Spectrosc. Radiat. Transfer, $\mathbf{7 0}$, 737-747, https://doi.org/10.1016/S0022-4073(01)00042-5.

Sun, Z., 2001: Reply to comments by Greg M. McFarquhar on 'Parameterization of effective sizes of cirrus-cloud particles and its verification against observations.' Quart.J. Roy. Meteor. Soc., 127, 267-271, https://doi.org/10.1002/qj.49712757116.

_ , and L. Rikus, 1999: Parameterization of effective sizes of cirrus-cloud particles and its verification against observations. Quart. J. Roy. Meteor. Soc., 125, 3037-3055, https://doi.org/ 10.1002/qj.49712556012.

Taylor, J. P., J. M. Edwards, M. D. Glew, P. Hignett, and A. Slingo, 1996: Studies with a flexible new radiation code. II: Comparisons with aircraft short-wave observations. Quart. J. Roy. Meteor. Soc., 122, 839-861, https://doi.org/10.1002/qj.49712253204.

Turner, D., M. Caddedu, U. Löhnert, S. Crewell, and A. Vogelmann, 2009: Modifications to the water vapor continuum in the microwave suggested by ground-based $150 \mathrm{GHz}$ observations. IEEE Trans. Geosci. Remote Sens., 47, 3326-3337, https:// doi.org/10.1109/TGRS.2009.2022262.

Voigt, C., and Coauthors, 2017: ML-CIRRUS-The airborne experiment on natural cirrus and contrail cirrus with the high-altitude long-range research aircraft HALO. Bull. Amer. Meteor. Soc., 98, 271-288, https://doi.org/10.1175/BAMS-D-15-00213.1.

Waliser, D. E., and Coauthors, 2009: Cloud ice: A climate model challenge with signs and expectations of progress. J. Geophys. Res., 114, D00A21, https://doi.org/10.1029/2008JD010015.

Wendisch, M., and A. Keil, 1999: Discrepancies between measured and modeled solar and UV radiation within polluted boundary layer clouds. J. Geophys. Res., 104, 27373-27385, https:// doi.org/10.1029/1999JD900242.

_ , D. Müller, D. Schell, and J. Heintzenberg, 2001: An airborne spectral albedometer with active horizontal stabilization. J. Atmos. Oceanic Technol., 18, 1856-1866, https://doi.org/ 10.1175/1520-0426(2001)018<1856:AASAWA > 2.0.CO;2.

__ , and Coauthors, 2004: Airborne measurements of areal spectral surface albedo over different sea and land surfaces. J. Geophys. Res., 109, D08203, https://doi.org/10.1029/ 2003JD004392.

— spectral irradiance: A case study for subtropical cirrus. J. Geophys. Res., 110, D03202, https://doi.org/10.1029/2004JD005294.

—, P. Yang, and P. Pilewskie, 2007: Effects of ice crystal habit on thermal infrared radiative properties and forcing of cirrus. J. Geophys. Res., 112, D03202, https://doi.org/10.1029/ 2006JD007899.

— ACLOUD/PASCAL multiplatform observations to unravel the role of clouds and aerosol particles in Arctic amplification. Bull. Amer. Meteor. Soc., 100, 841-871, https://doi.org/ 10.1175/BAMS-D-18-0072.1.

Wirth, M., A. Fix, P. Mahnke, H. Schwarzer, F. Schrandt, and G. Ehret, 2009: The airborne multi-wavelength water vapor differential absorption lidar WALES: System design and performance. Appl. Phys. B, 96, 201-213, https://doi.org/ 10.1007/s00340-009-3365-7.

Wolf, K., A. Ehrlich, T. Hüneke, K. Pfeilsticker, F. Werner, M. Wirth, and M. Wendisch, 2017: Potential of remote sensing 
of cirrus optical thickness by airborne spectral radiance measurements at different sideward viewing angles. Atmos. Chem. Phys., 17, 4283-4303, https://doi.org/10.5194/acp-174283-2017.

Wood, R., 2000: Parametrization of the effect of drizzle upon the droplets effective radius in stratocumulus clouds. Quart J. Roy. Meteor. Soc., 126, 3309-3324, https://doi.org/10.1002/ qj. 49712657015 .

Wylie, D. P., and W. P. Menzel, 1999: Eight years of high cloud statistics using HIRS. J. Climate, 12, 170-184, https://doi.org/ 10.1175/1520-0442-12.1.170.

Xie, S., and Coauthors, 2010: Clouds and more: ARM climate modeling best estimate data. Bull. Amer. Meteor. Soc., 91, 13-20, https://doi.org/10.1175/2009BAMS2891.1.

Yang, H. Y., S. Dobbie, R. Herbert, P. Connolly, M. Gallagher, S. Ghosh, S. M. R. K. Al-Jumur, and J. Clayton, 2012: The effect of observed vertical structure, habits, and size distribution on the solar radiative properties and cloud evolution of cirrus clouds. Quart. J. Roy. Meteor. Soc., 138, 1221-1232, https:// doi.org/10.1002/qj.973.

Yang, P., L. Bi, B. A. Baum, K. N. Liou, G. W. Kattawar, M. I. Mishchenko, and B. Cole, 2013: Spectral consistent scattering, absorption, and polarization properties of atmospheric ice crystals at wavelengths from 0.2 to $100 \mu \mathrm{m}$. J. Atmos. Sci., 70, 330-347, https://doi.org/10.1175/JAS-D-12-039.1.

Yi, B., P. Yang, B. A. Baum, T. L'Ecuyer, L. Oreopoulos, E. J. Mlawer, A. J. Heymsfield, and K.-N. Liou, 2013: Influence of ice particle surface roughening on the global cloud radiative effect. J. Atmos. Sci., 70, 2794-2807, https://doi.org/10.1175/ JAS-D-13-020.1.

Zhang, Y., A. Macke, and F. Albers, 1999: Effect of crystal size spectrum and crystal shape on stratiform cirrus radiative forcing. Atmos. Res., 52, 59-75, https://doi.org/10.1016/S01698095(99)00026-5. 